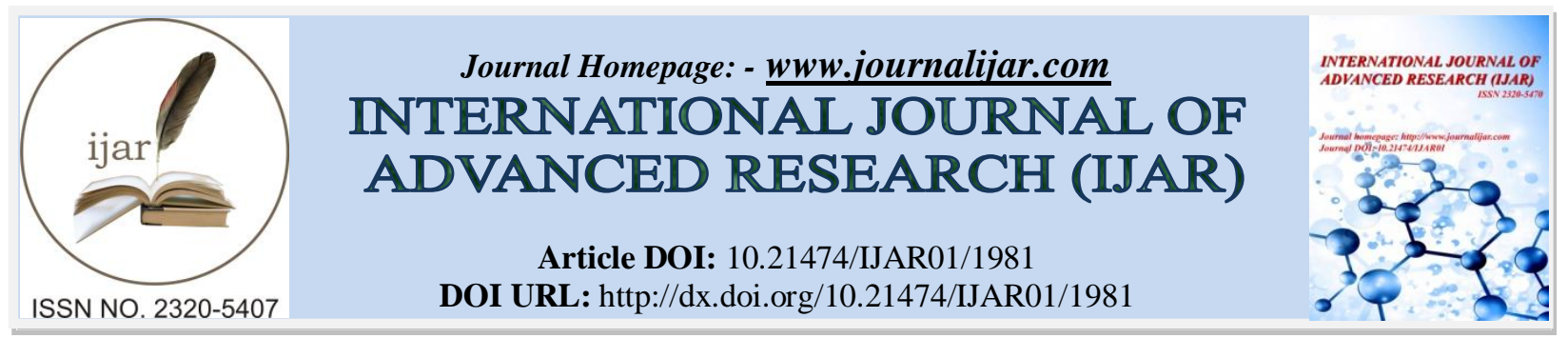

RESEARCH ARTICLE

\title{
"A STUDY TO ASSESS THE EFFECTIVENESS OF COMMUNICATION BOARD ON THE LEVEL OF SATISFACTION OF COMMUNICATION PATTERN AMONG PATIENTS ON MECHANICAL VENTILATOR IN BOMBAY HOSPITAL AT INDORE IN THE YEAR 2014-2015”
}

Mrs. Dorwin Das.

HOD of Medical Surgical Department, Bombay Hospital CON, Indore.

\section{Manuscript Info}

Manuscript History

Received: 12 September 2016

Final Accepted: 22 October 2016

Published: October 2016

Key words:-

Radiotherapy, Collagenase gene, cancer and Swiss mice.

\section{Abstract}

Objectives of the study:-

- To assess the post-test level of satisfaction of the communication pattern among the patient on mechanical ventilator in both experimental and control group.

- To compare the post-test level of satisfaction of communication pattern among the patients on mechanical ventilator between experimental and control group.

\section{Hypothesis:-}

- There will be significant difference in mean posttest level of satisfaction in communication pattern among the patients on mechanical ventilator between experimental and control group.

Assumptions:-

Patient with mechanical ventilator experiences communication problem So,

- Communication board is effective for ventilator patient.

- It increases patient participation and patient satisfaction with health care.

- It improves the staffing efficacy.

Limitations:-

- This study is limited to patient on mechanical ventilator.

- This study is limited to conscious patient under mechanical ventilator.

Delimitations:-

- Unconscious patients are not involved in this study.

- Those patients who are not willing to participate.

Methodology:-Quasi-experimental research approach was used for the study. Non-probability convenience sampling was used as sampling technique and 20 patients on mechanical ventilator in Bombay Hospital, Indore were selected. Data collection was done with the help of demographic performa and structured questionnaires.

Conclusion of the study shows that there is significant level of satisfaction of Communication pattern of patient in mechanical ventilator using a communication board in experimental group, while there is little or no satisfaction in control group. 
Findings:-This study is to assess the effectiveness of communication board on level of satisfaction of communication pattern among patients on mechanical ventilator. It was formulated that the mean posttest in experimental group is significantly higher than mean posttest in control group. The study assumed that communication board is effective in mechanically ventilator patient.

The present study is based on the concept of communication board to the conscious patients on mechanical ventilator.

The investigator adopted the Widenbach's helping art of clinical art theory (1964), which describes the desired situation and way to attain. It directs action towards the explicit goals.

This study made use of a quantitative study with experimental and control group post-test research design. The mechanically ventilator patient in Bombay hospital, Indore. Non-probability sampling technique was used to select 10 patients in mechanical ventilator in experimental and control group from ICU based on certain determined criteria.

The investigators prepared a structured knowledge questionnaire consisting of 17 questions to assess the level of satisfaction of communication board on mechanically ventilated patients in ICU in experimental group with communication board and control group without communication board.

The actual study was conducted on 20 patients on mechanical ventilator in Bombay Hospital, Indore.

Following the post-test planned teaching on communication board on mechanical ventilator patient had given. The data obtained were analysed in terms of objectives and hypotheses using descriptive and inferential statistics.

Findings of the study proved that the communication board on level of satisfaction on mechanical ventilator patient. The mean post-test score in experimental 8 group was 46.4 and the mean post-test score of control group was 32.9. The post-test score proved that the communication board on level of satisfaction on mechanical ventilator to improve the communication pattern in experimental group than control group without communication board. The effectiveness of communication pattern in mechanical ventilator patient was tested in terms of level of satisfaction in communication and finding showed that it was significant at $7.00 *$ Level $[\mathrm{t}(18)=2.18$

On the whole, carrying out the study was really an exciting experience to the investigator. It also helped a great deal to explore and improve the level of satisfaction in communication pattern of mechanically ventilated patients and the researcher.

Implication:- The findings of the study have implications for nursing practice, nursing education, nursing administration and nursing research. $\bullet$

Nursing practice:- Continuous in-service education is an important tool for health care agency. The findings of the study indicated that there is a need for the continuous in-service education regarding communication board to improve the level of satisfaction of communication in mechanically ventilated patient and to find out the problems of patient and to improve the quality care. 


\section{- Nursing education:-}

o Awareness can be given to the nursing staff and family members so as to improve the communication pattern with mechanically ventilated patient.

o It can be used as an informational aid to student nurse to acquire the knowledge and skills in enabling effective communication with mechanically ventilated patient.

o The nursing curriculum has to focus on enabling the nursing students to develop communication skills using communication board in mechanically ventilated patient.

o Nursing personnel working in various health care setting should be given in-service education to update knowledge and planning appropriate interventions to improve communication pattern in mechanical ventilated patient.

- Nursing administration:- The present study is proposed to help the hospital administrator to strategically plan $\square$ and meet the health needs of mechanically ventilated patient who are unable to communicate their problems and basic needs effectively with the use of communication board.

- Nursing research:- There is a need for extended and intensive nursing research in the areas of Intensive Care Unit. Especially in India only few studies were reported regarding effectiveness of communication board in level of satisfaction of communication in mechanically ventilator patient. It is important to know the level of satisfaction of communication pattern in mechanically ventilated patient.

Recommendations:-

On the basis of findings of the study, it is recommended that:

- A similar study can be conducted by taking a large sample to generalize the findings.

- A comparative study may be conducted to find out the effectiveness of communication board on level of satisfaction in mechanically ventilator patient regarding the same topic. • A study can be conducted to identify level of satisfaction of communication board in mechanically ventilator patient.

Copy Right, IJAR, 2016,. All rights reserved.

\section{Introduction:-}

Communication is the exchange \& flow of information and ideas from one person to another. It involves sender transmitting an ideas, information, feelings to a receiver. Effective communication occurs only of the receiver understand the exact information or ideas that the sender intended to transmit. Many of the problems that occur in an organization all either direct result of people failing to conclusion can cause good plans to fail.

Communicating effectively with ventilator dependent patient is essential so that various basic physiological and psychological needs can be conveyed \& decision, wishes \&desires about the plan of care and end of life. Decision can be expressed, numerous methods can be used to communicate, including gestures, head nods, mouthing of words, writing, use of letter, pictures, boards \& common words or phrases tailored to meet individualized patient needs, high tech alternatives.

Communication devices are available for more complex cares. Various option for patients with a tracheostomy tube include partial or total cough deflation and use of peaking value. It is important for nurses to correct communication needs, identify appropriate alternative communication strategies. Create a customized care plan with the patient, the patient's family and other team members, ensure that the care plan is variable and accessible to all staffing interacting with the patient and continue to collaborate with colleagues from all discipline to promote effective communication with non vocal patients. 
Communication holds a central space in our lives, everyone communicates in a diverse ways in varied settings. However commonplace the act of communication it is difficult to analyze. The more we learns to analyze their processes, the more complex they appears to be. Mechanical ventilation is a method of mechanically assisting or replacing spontaneous breathing with machine known as ventilator, this procedure requires a tube to be introduced into the trachea for air to flow in and out, endotrachel tube passing through the vocal cords make speech impossible, thus dramatically altering the communication process.

It became necessary to develop a strategy that can help in communicating needs of patient with a view to improve interpersonal relationship between nurse and patients however very little systematic researches has been done to determine the use of communication board, which has the potential to improve communication.

Communication board are made by experts in the field of communication and the lack the contribution patients who have undergone communication difficulties due to mechanical ventilator, hence there is need to explore the patient needs and identify content that they want in communication board.

\section{Background of the study:-}

The literature supports nursing interventions to maximize communications in mechanically ventilated patients .Yet limited research exists on patient's perception of the helpfulness of health care practitioner interventions to enhance communication .In addition the level of frustration experienced by the patients has not been reported. Thus further research is necessary to examine patient's perspectives of helpfulness of healthcare practitioner intervention that enhance communication of the mechanically ventilated patients.

Some patients receiving mechanical ventilator experience an intensified need to communicate while their ability to do so is comprised as the endotracheal tube prevents speech, although the use of a communication .A cycle of confusion ensures, involving misunderstanding between nurses and patients during attempts to convey messages that are misinterpreted or understood. Anxiety and frustration build and contribute to the negative emotions and feeling of dependency dehumanization and futility.

Patients have described their inability to communicate during mechanical ventilation as frustrating scary and horrible.

Interventions that health care practitioners can use include interpreting a patient nonverbal forms of communication such as mouthing, gesticulating, nodding, \& writing. Such non-verbal methods not only require energy but are tiring and emotionally draining for these patients. The use of a board as a intervention to enhance communication has been proposed by health care practitioner.

Thus, further research is necessary to examine patient perception of the utility of a communication board and to identify the content and format patient want in a board. To enhance communication with patients few descriptive or empirical studies addressed the content format of the devices or patients perspective on decreasing frustration with communication.

Patient receiving mechanical ventilation have reported communication difficulties as this number one problem while intubated Gries \& Femsler et al. 2002, Strovsky, Rudy \& Dragoneltee 1988.

Patient inability to communicate results in unrecognized pain feeling of loss of control, depersonalization, anxiety, fear and frustration (Criner \& Issac 1995; Dickerson, Stone, Panchura \& Usiak 2002 Gries \& Femsler 1988, Hefsteindothr 1996, Health, 1989; Johnson and Secton 1990, Riggio, Singer, Hachman \& Sneider by journal 1982, Stein-Parbury \& McKinley 2000)

Patients may become anxious when their needs are not met during periods of mechanical ventilation because of their inability to verbally communicate with family and health care provider (Levine, Koester \& Ket, 1987)

Carroll, S M (2004) Non vocal ventilated patient perform of being Understood, western journal of nursing research $26(1), 85-103$ 


\section{Need for the study:-}

"Need for effective use of the best communication available"

Communication difficulties are all too often devasting in health care setting \& it can often create huge barriers between patients and health care staff.

In health care setting communication break down between patient \& caregiver can have direct consequences such as increased patient pain, misdiagnosis drug treatment errors, unnecessary extension in length of hospital stay and even death.

Communication is the process of sharing ideas, thoughts, opinion, message, feelings and information. Communication problems caused by intubations and cognitive, sensory, or language deficits that distance the patients from care givers and loved ones. Mechanical ventilation and use of paralytic and sedative agents impair communication between patients and others. Physical restraints used to prevent disruption of medical devices further limit patients' ability to gesture or use alternative communication techniques.

The ability to fully express their needs, wishes about end-of-life care, or final messages to loved ones.

In studying communication-related responses among non-speaking patients treated with mechanical ventilation, researcher found that patients had greatest difficulty in communicating with their family members.

Most surveys of patients and qualitative accounts of the experience of mechanical ventilation are done retrospectively with patients who survive critical illness. Under-recognition and disturbingly high levels of pain continue to be common among critically ill patients, many of who cannot communicate symptoms or request relief. Impairment in communication is a barrier to accurate assessment and optimum management of pain, delirium, and other signs and symptoms in the ICU. The extent to which non - surviving, critically ill patients are able to communicate and how and with whom. Health care providers need to be intervening on behalf of the mechanically ventilated patients to promote the communication. Health care practitioners can facilitate the communication by being kind and patient, offering verbal reassurance and important information and being present and available at bedside.

Mechanically ventilated patients were surveyed and said that a communication board would have helped them to better express their needs to hospital health care workers. The patients noted that communication board helped both the speed and efficiency with which they communicated with their caregiver.

The article describes a study conducted by a group of doctors and nurses to determine the level of frustration patients experience when trying to communicate during mechanical ventilation, their level of frustration with the use of a communication board, and their perceptions of the appropriate format and content of this communication tool. Sixty-nine percent of patients in the study said that they would have experienced less frustration during mechanical ventilation if they had used a communication board. The same patients identified specific characteristics the communication board should exhibit to facilitate communication with health care providers.

Many researchers assessed the effectiveness of communication board to meet the unmet needs of patient to reduce their anxiety and frustration among mechanically ventilated patients. So the investigator had an interest to assess the effectiveness of communication board on communication pattern and level of satisfaction.

Problem statement:-

"A study to assess the effectiveness of communication board on the level of satisfaction of communication pattern among patients on mechanical ventilator in Bombay Hospital, Indore in the year 2014 - 2015”.

\section{Objectives of the study:-}

- To assess the post-test level of satisfaction of the communication pattern among the patient on mechanical ventilator in both experimental and control group.

- To compare the post-test level of satisfaction of communication pattern among the patients on mechanical ventilator between experimental and control group. 


\section{Hypothesis:-}

There is significant difference in mean posttest level of satisfaction in communication pattern among the patients on mechanical ventilator between experimental and control group.

\section{Assumptions:-}

Patient with mechanical ventilator experiences communication problem So,

- Communication board is effective for ventilator patient.

- It increases patient participation and patient satisfaction with health care.

- It improves the staffing efficacy.

\section{Limitation:-}

- This study is limited to patient on mechanical ventilator.

- This study is limited to conscious patient under mechanical ventilator.

\section{Delimitation:-}

- Unconscious patients are not involved in this study.

- Those patients who are not willing to participate

\section{Operational definitions:-}

1) Effectiveness:-

The outcome of the communication board in improving the communication pattern of the patient on mechanical ventilator, which is assessed by checklist.

\section{2) Communication board:-}

Communication board or signboard is the board with various signs, which help the patient on mechanical ventilation to express their needs until they are extubated / able to speak.

\section{3) Communication pattern:-}

The process by which the ventilated patient express his or her needs, views, ideas, feelings or giving some information during his or her period of stay on mechanical ventilator.

\section{4) Level of satisfaction:-}

The feeling of contentment obtained when the communication needs are met, which is measured through checklist.

5) Mechanical ventilator:-

Mechanical ventilator is a machine that generates a control flow of gas in to the patient's airway

\section{Study outcome:-}

- The study will help the nurses to understand the importance of communication board on the level of satisfaction in communication pattern of patient on ventilator

- The study will provide an opportunity for nurses to use communication board in ICUs for improving the communication ability of the patients on ventilator.

\section{Conceptual framework:-}

\section{Concept:-}

Concept is defined as a complex mental formulation of an object or an event that is from the individual perception and experience.

\section{Conceptual framework:-}

The present study is based on the concept of communication board to the conscious patients on mechanical ventilator.

The investigator adopted the Widenbach's helping art of clinical art theory (1964), which describes the desired situation and way to attained. It directs action towards the explicit goals. This theory has three factors;-

- Central purpose

- Prescription

- Reality 


\section{Central purpose:-}

It refers to what the nurse want to accomplish. It is an overall goal towards which a nurse strives. Central purpose of this study is to improve the level of satisfaction in communication pattern of patients in mechanical ventilator.

\section{Prescription:-}

It refers to plan of care for a patient. It will specify the nature of action that will fulfill the nurse's central purpose.

\section{Reality:-}

It refers to the physical, psychological, emotional and spiritual factors that comes in to situations involving the nurses

The five realities identified by Widenbach are agent, recipient, goal, mean activities and framework.

- Agent : nurse investigator

- Recipient : conscious patients on ventilator

- Goal : improve the level of satisfaction of communication pattern of patients on ventilator.

- Mean activities : provide communication board for experimental group

- Frame work : ICU of Bombay hospital, Indore

The conceptualization of nursing practice according to this theory consists of three steps as follows; STEP I: - identifying the needs for help in communication. STEP II:-ministering the needed help

STEP III: -validating for help was met

STEP:-I - Identifying the needs for help in communication:

The investigator providing communication board to the patients on ventilator. With the help of communication board patients are showing their wants and needs

STEP: - II- Ministering the needed help:

After identifying the need of patient provides intervention:

STEP:-III- Validating for help was met

Accomplished by means of post-test assessment level of satisfaction in meeting the basic needs of patients on ventilator for experimental and control group.

\section{Review of literature}

The review of literature for the present study is grouped under the following

headings.

Review of literature related to;-

1) Review of literature related to Effectiveness of communication board.

2) Review of literature related to level of satisfaction of the communication pattern

3) Review of literature related to communication pattern of mechanical ventilator patients.

\section{Review of literature related to effectiveness of communication board:-}

1. LANCE PATAK ETAL (2004):It was conducted a descriptive study using qualitative and quantitative methods a total of 29 critically ill patients extubated within the last $24 \mathrm{hrs}$ it was found that $62 \%$ of patients extubated $(\mathrm{n}=18)$ reported a high level of frustration in all staffing interacting with the patient and continue to collaborate with colleagues from all discipline to promote effective communication with non-vocal patients.

ELSEIVER (2006): conducted an experimental study on communication board may be an effective intervention for decreasing patient's frustration and facilitating communication. Most patient's receiving mechanical ventilation experienced a moderate to a high level of frustration when communicating their needs. In this study a communication board, is used patiently during mechanical ventilation, has been shown to alleviate frustration with the communication. Patient have specific ideas about what terms and ideograms are useful for a communication board, further research is needed to test the effects of a communication board and other methods of facilitating communication on outcomes such as satisfaction and anxiety of patients adequate and appropriate management of pain and length of mechanical ventilation time and hospital stay. 
MISTRYETAL (2008): A study was conducted on same topic that communication is the exchange and flow of information and ideas from one person to another, it involves sender transmitting an ideas, information or feeling Communication is a critical component in the hospital settings where its impact is seen in the patients overall medical care, psychological to a receiver .effective communication occur only of the receiver understand the exact information or ideas that the sender will transmit. Many of the problems that occur in an organization all either direct result of people failing to confusion can cause good plans to fail.

\section{World health organizations, world health statistics:-}

(2008) FRANCE: A descriptive study was conducted in France on same topic and it is based that communication communicating their needs while being mechanically ventilated. There was no significant difference between the duration of intubations and the level of frustration. Mechanically ventilated patients experience 'a high level of frustration when communicating their needs the health care providers have a significant impact on mechanically ventilated patient's experience

\section{Pressman harvey \& heather smith (2014):-}

A study was conducted on communicating effectively with ventilator dependent patients is essential so that various men residing in a nursing home, is presented three major factors are found to operate cumulatively in increasing Kay's overall communication effectiveness." basic physiological and psychological needs can be conveyed \& decision wishes and desired about the plan of care and end of life decision making can be expressed ,numerous methods can be used to communicate including gestures ,head nods, mouthing of words writing, use of letter ,pictures boards and common words of phrases, tailored to meet individualized patient needs , high tech alternatives ,communication devices are available for more complex cases, various option for patients with a tracheostomy tube include partial or total cuff deflation $\&$ use of a peaking value. It is important for nurses to assess communication needs, identify appropriate alternatives communication, strategies create a customized care plan with the patient . the patient 's family and other team members, ensure that the care plan is visible and accessible to holds a central space in our lives; everyone communicates in a diverse ways in varied settings, however commonplace the act of communication. It is nonetheless difficult to analyze, the more we learns to analyze the process the more complex they appears to be functioning and social interaction. There is a considerable rise in the number of patients who are hospitalized and require advanced medical care like mechanical ventilation person to another ,it involves sender transmitting an ideas, information or feeling Communication is a critical component in the hospital settings where its impact is seen in the patients overall medical care, psychological to a receiver effective communication occur only of the receiver understand the exact information or ideas that the sender will transmit. Many of the problems that occurs in an organization all either direct result of people failing to confusion can cause good plans to fail.

\section{Review of literature related to level of satisfaction of the communication pattern:-}

1. LINDGREN \& AMES, HENNERMAN, DRACUP, GANJ, MOLAYEME \& COOPER(2001) \& (2002) Mechanically ventilated patients can achieve decreased length of ventilator days as well as decreased length of ICU stay by an average of $2.7 \& 3.6$ days , respectively . multidisciplinary term collaboration with the pt is necessary for achieving there stated out comes "Give the pt paper \& pencil to determine if hand working is legible, picture \&alphabet boards can be useful as well one such tool is the Ezboard "the vidatak EZ board is distributed internationally and sold through the AACV as the only research based communication tool shown to reduce frustration and improve patient satisfaction

2. STARRY .M. CARROLL (2004) A study conducted on used metasynthesis and understanding of non vocal mechanically ventilator patients experience with the communication the final sample (n-111) included 12 qualitative studies. The data methods and the theoretical framework were interpreted The samples are divided into two groups. In the first group, the characteristics of non vocal ventilated patient's communication were those not understood which resulted in loss of control and emotional responses

\section{AMERICAN BOARD OF INTERNAL MEDICINE (2005-2009)}

Data for this study were collected retrospectively from a data base of patient satisfaction surveys completed for internal medicine residents at different level of training patient satisfaction was measured with the aggregated EVGFP ( Excellent, Very good, Good, Fair, Poor) a total of 768 patient rating forms were completed for 67 residents during their 3years of residency training in post graduate year (PGV), the residents had a mean rating of $4.37+0.48$ compared to a mean rating of $4.37+0.45$ in their PGV -3 year. Analysis of variance indicated no 
significant difference by PGV level Our findings demonstrated that resident communication skills \& patient satisfaction do not decline during the 3years of residency .this is contrary to our hypothesis that patient satisfaction would worsen as residents progressed through training.

4. ANNIE (2007) : performed an experimental control trial of 60 patients, randomized to use the vidatakez board or routine care in India. The results of this study demonstrated that $73 \%$ patients without the ez board found their communication process was inadequate; however with the board, $80 \%$ found their communication was adequate without the ez board $77 \%$ was satisfied. Of those who used the vidatakez board $80 \%$ satisfied with the board $20 \%$ moderately satisfied and non-reported unsatisfied. Nurses however reported 53\% satisfaction, $30 \%$ moderately satisfied and $17 \%$ unsatisfied overall, the patients with the vidatakez board reported higher satisfaction with the communication $(\mathrm{p}<.001)$ and this was co-related to their satisfaction with the vidatakez board $(\mathrm{p}<.01)$.

5. REED (2008): surveyed nurses and patients regarding methods used to communicate. Pre- intervention assessments reported $60 \%$ of mechanical ventilator patients were extremely frustrated with their inability to communicate and $75 \%$ of nurses perceived their methods and resources to be inadequate. Post intervention assessment reported $51 \%$ of patients preferred the EZ board as their best method compared to other communication aids and basic methods and 58\% of nurses reported the EZ board as the most beneficial method

6. WORLD HEALTH ORGANIZATION,WORLD HEALTH STATISTICS 2008, FRANCE: Communication holds a central space in our lives every one of communication itis nonetheless difficult to analyze.

Communication is a critical component hospital settings where its impact is seen in the patients overall medical care, psychological functioning and social interaction. there is a considerable rise in the no.of patients who are hospitalized and require advanced medical care like mechanical ventilation $\mathrm{s}$.

\section{Review of literature related to Communication pattern of mechanical ventilator patients:-}

1. HEATH \& BRYANT, (2000): Especially influential on organizational communication, systems theory explains how and why people form groups, each of which is a system as well as part of a larger system. Its focus is on the whole system rather than on its parts, and how these parts interact to affect the whole system. Infante, Rancer and Womack (1997) define a system as hierarchical — a set of interdependent units working together to adapt to a changing environment. It can be divided into smaller subsystems or incorporated with other systems to create larger systems, referred to as suprasystems or environments (Heath \& Bryant, 2000). A systems approach to organizational communication expands the basic model of sender-receiverto feature communication networks; this explains how systems adapt to their environments (Heath \& Bryant, 2000).

2. HUPCEY AND ZIMMERMAN,(2007): A study on the difference in perceptions between intubated patients during illness . grounded theory was used to explore the meaning of knowing and not knowing and not knowing and the process by which knowing occurs.unstructured interviews were done with 14 patients. Showed that critically ill patients have a strong need to know throughout and after their discharge from intensive care unit . nurses must address this need for constant reorientation to the past and present in these patients . In addition , adequate nursing staff must be for these patients.

3. JOHNSON AND SEXTON (2007): In this qualitative study, it was interviewed $n=14$. The inability to speak was identified by all participants as causing distress from mild to extreme. In addition other factors causing distress including pain \& discomfort from the endotracheal tube. Suctioning inability to determine time and noise. This distressing factors can be alleviated by health care professionals.

4. JOHNSON AND SEXTON (2007): In this qualitative study, it was interviewed $n=14$. The inability to speak was identified by all participants as causing distress from mild to extreme. In addition other factors causing distress including pain \& discomfort from the endotracheal tube. Suctioning inability to determine time and noise. This distressing factors can be alleviated by health care professionals.

5. ROTUNDI et.al(2008): A study was conducted on 150 subjects with an objective to describe stressful experience of adult patients who receive mechanical ventilator for more than 48 hours two third of the se patients remembrance 15 endotracheal tube and $\backslash$ or being in an intensive care unit experiences remembered were 3 (of 7) and 9(of 22), respectively the study found that many subjects perceived inability to communicate was subjected to numerous stressfull experiences which was found moderately to extremely bothersome. 
6. KEFANGWANG et.al, (2008): conducted a phenomenological approach and giorgi's phenomenological analysis procedure was used to analyze the data . participants $(n=1)$ surviving from mechanical ventilator were interviewed in depth, described their experience which were being in unconventional environment . physical sufferings , psychological sufferings and self -encouragement and self reflection enhanced patients in Intensive care

7. PATRICK WS MARIE (M. PRETER K ANTOMIOC DAVID R. HOLMES (2009): stat percutaneous d coronory intervention versus coronory artery bypass grafting for severe coronary artery.

The new England journal of medicine (2009)

Critical care staff who manage intubated patient often experience difficulty with one of the most basic human communication patient's with endotracheal or tracheostomy tube are unable to communicate verbally because of the placement of the tubes and inflation of the tubes cuff which prevent passage of air across the vocal cord despite the inability to produce speech, these patient can communicate effectively via other methods.Intubated patient's communicate with nurses, other clinicians and family members primarily, through gestures, head nodes, mouthing of words and writing.

Other communication method include letter /pictures, boards lists of common words or phrases tailored to meet individual patient's needs and high tech alternatiuves communication devices. Various option for patient's with a tracheostomy tube include partial or total cuff deflation and use of a speaking valve is certain patient's who are in stable condition specially tracheostomy tubes are also available to allow speaking while the cuff of the tracheostomy tube is inflated.

Although communication with patients in the I C U is usually focused on basic needs related to physical comfort such as positioning or suctioning communication is often an important component of end-of-life decision making patient may need to express their final wishes to family,friends and providers

IRENE GROSSBACH et.al, 2009; A study conducted on communicating effectively with ventilator dependent patients is essential so that various basic physiological and psychological needs can be conveyed and decisions, wishes and desires about the plan of care and end- of - life decision making can be expressed. Numerous methods can be usewd to communicate

,including gestures ,head nodes ,mouthing of words ,writing , use of letter/ picture boards and common words or phrases tailored to meet individualized patient needs hightech alternative communication devices are available for more complex cases various options for patients with a tracheostomy tube include partial or total cuff deflation and use of a speaking valve . it is important for nurses to assess communication strategies; create a customized care plan is visible and accesible to all staff interacting with the patient ; and continue to collaborate with colleagues from all disciplines to promote effective communication with non vocal patients

8. FATMA ETI ASLAN( 2009): conducted a descriptive study with patient's $(n=300)$ in a cardiac surgery ICU postoperatively for a minimum of $48 \mathrm{hrs}$, had a sternal incision chest tube and required mechanical ventilation. Most patients described their pain as aching $(n=177)$ and throbbing $(n=154)$, the presence of chest tube $(n=95)$ endotracheal tube suctioning $(n=47)$ change of dressings $(n=27)$ and use of air mattresses $(n=20)$ were also identified as painful experiences for patient.

9. RADTKE JVI,BAUMAN BM, GARRETT KL, HAPP MB 2011: communication problems are experienced by nonspeaking, critically ill patients in the intensive care unit (ICU) have serious implications for the physical and psychological well -being of patients and the quality of their care. These problems are most profound for those with prolonged critical .who a re the highest risk of dying. Recently speech language pathologist (SLP) services have been used to provide augmentive and alternative communication (AAC) strategies across different levels of illness severity and communication impairement for non speaking patients in the ICU,

\section{Summary}

This chapter dealt with review of literature related to communication, communication of intubated patient and effectiveness of communication board. 


\section{Chapter 3}

\section{Research methodology:-}

The study is designed to assess the effectiveness of communication board on the level of satisfaction of communication pattern of patients on ventilator. This chapter includes research design, description of setting, variables, population and sample, sampling technique and sampling size, criteria for sample selection, description of tool, validity, data collection procedure, pilot study and data analysis method.

\section{Research approach:-}

Quasi-experimental research approach was adopted for the study.

\section{Research design:-}

The research design adopted for this study is non-randomized posttest only experimental design.

Variables:-

Independent variable: communication board.

Dependent variable: level of satisfaction of communication pattern in mechanical ventilator patients

Extraneous variable: age, gender, education, occupation and

Area of residence.

\section{Population:-}

The population of this study comprises of patient on mechanical ventilator in icu.

\section{Description of setting:-}

The study was carried out in bombay hospital (experimental group) and bombay hospital (control group), indore, bombay hospital is equipped with 600 beds and it has various departments like icu, causuality and is nabh accrediated. Bombay hospital is about $10 \mathrm{~km}$ away from railway station indore.

The investigator selected these setting for the availability of the sample and feasibility of this study.

\section{Sampling technique:-}

\section{The sample:-}

The sampling of this study comprises of patient on ventilator admitted in icu, during the study period and those who met the sampling criteria.

\section{Sample size:-}

The sample size for this study was 20 patients on ventilator. Among them 10 patients of bombay hospital were selected for experimental group and other 10 patients of bombay hospital were selected for control group.

\section{Sample technique:-}

The investigator selected 20 patients on ventilator through non- probability convenience sampling technique.

\section{Criteria for sample selection:-}

Inclusion criteria:-

1. Conscious patient under mechanical ventilation

2. Patients with normal mental status.

\section{Exclusion criteria:-}

1. Patients who are not willing to participate in the study.

2. Patient who are unconscious 
Research designs

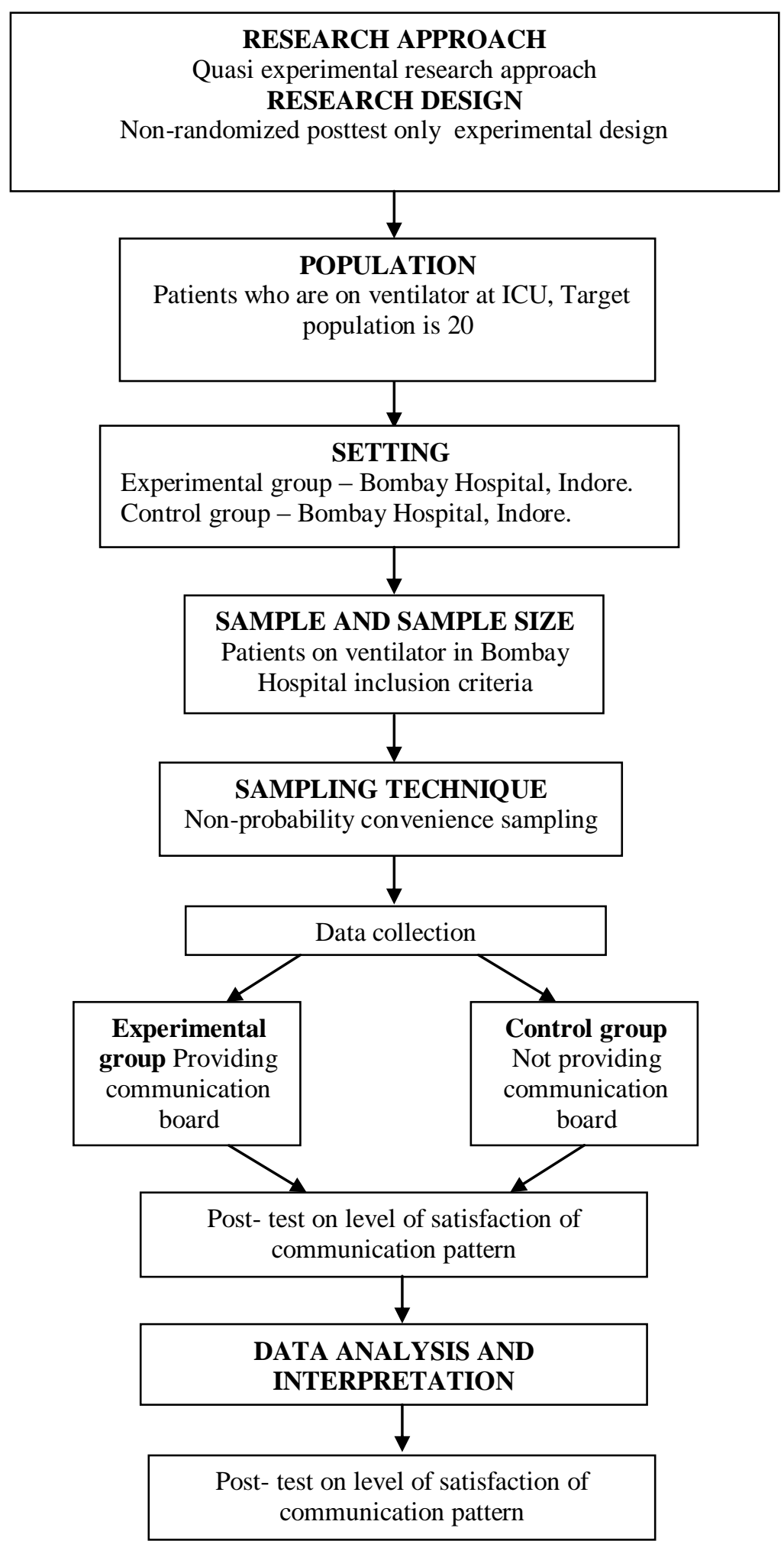




\section{Development and description of the tool}

The tool consists of:

\section{Section -1: socio-demographic variables}

Demographic variables like age, gender, religion, education, occupation, area of residence, duration of intubation, use of any anxiolytics, weaning duration and diagnosis are collected by using a semi structured interview schedule.

Section-2: a rating scale to assess the level of satisfaction of communication pattern on mechanical ventilator patients.

A semi structured interview schedule was used to assess the level satisfaction in meeting the basic needs of patients on ventilator. According to scoring the patients were classified into various Categories

Table no. 1: showing the rating scale of level of satisfaction of communication pattern on mechanical ventilator patients.

\begin{tabular}{|c|c|}
\hline SCORE & LEVEL OF SATISFACTION \\
\hline $17-34$ & Not satisfied \\
\hline $35-51$ & To some extend \\
\hline $52-68$ & Satisfied \\
\hline
\end{tabular}

Validity:-

Validity of the tool was obtained from four Experts in the field nursing from Bombay Hospital, college of nursing. We have taken validity from HOD of Community Health Nursing \&M.Sc.

Lecturers of various specialities.

\section{Content validity:-}

Content validity refers to the degree to which an instrument measures what it supposed to measure

The rating scale along with problem statement, objectives of the study, hypothesis, operational definition, inclusion and exclusion criteria and criteria checklist were submitted to four experts to ensure content validity Demographic performa: there were 10 items in demographic performa. There was $100 \%$ agreement for all items. Structured interview schedule for assessing the level of satisfaction of communication pattern in mechanical ventilator patient.

There were 17 items in the tool and there was $100 \%$ agreement for all items.

\section{Post-testing of the tool:-}

Post test is the process of measuring effectiveness of tool .it will help the investigator to determine whether directions are understandable and are able to identify any trouble in some portion of the tool.

The tool was post- tested on a sample of 10 at ICU.

The patients expressed that all instructions and the questionnaires were clear and understandable

\section{Reliability:-}

Reliability of the tool is the degree of consistency with which is it measures the attributes it is supposed to be measured.

The reliability of the tool was determined by administering the tool by rating scale method to 10 patients on mechanical ventilator in ICU responded did not find any difficulty in understanding and answering the questions. The reliability coefficient of tool was calculated using test retest method. The reliability tool was found for level of satisfaction of communication pattern is $r=0.75$

This was statistically significant this indicates that the tool was reliable.

\section{Pilot study:-}

Pilot study was conducted to find out the feasibility of the study. A formal permission was obtained from the concerned authority of the hospitals. It was conducted with a sample size of 20 patients on ventilator, 10 patient from ICU for experimental group and 10 patients for control group. The collected data as analyzed by using descriptive and inferential statistics. The pilot study revealed that the study is feasible and practical. 


\section{Methods of data collection:-}

\section{- Ethical consideration:-}

Written permission was obtained from the nursing superintendent Bombay Hospital, Indore. Informed written consents were obtained from the patients and relatives.

\section{- Data collection procedure:-}

The data was collected over a period of. Investigator selected 10 samples for control group from Bombay Hospital by using non-probability convenience sampling technique. First investigator introduced himself to the patients and explained the purpose of the study and got consent from relatives. Then the communication board was provided for the patients in experimental group. They are explained about how to use the communication board. The control groups were not provided communication board and they expressed their wants and needs without any assistive devices.

After the patient weaned from the ventilator data was collected by using semi structured interview schedule for assessing the level of satisfaction in meeting the basic needs. The collected data was analyzed and interpreted.

\section{Plan for data analysis:-}

The data will be analyzed by using both descriptive and inferential statistics. The data related to demographic variables will be by find out the mean median, mean percentage, and standard deviation. And hypotheses is tested by using the unpaired ' $t$ ' test. 


\section{Chapter 4}

\section{Data analysis and interpretation:-}

This chapter deals with the analysis and interpretation of the data collected using a structured questionnaire and observation checklist. Data collected from 20 -ventilator patient and was analyzed according to the objectives and hypothesis of the study.

Abdellah and Levine (1979) stated that interpretation of tabulated data can bring to the real meaning of the finding of the study.

\section{Objectives:-}

- To assess the post-test level of satisfaction of the communication pattern among the patient on mechanical ventilator in both experimental and control group.

- To compare the post-test level of satisfaction of communication pattern among the patients on mechanical ventilator between experimental and control group.

\section{Hypothesis:-}

H1;-there is significant difference in mean posttest level of satisfaction in communication pattern among the patients on mechanical ventilator between experimental and control group.

\section{Organization and presentation of data:-}

The collected data are organized and presented under the following sections:

Section 1: Frequency and percentage of socio-demographic variables of experimental and control group

Section 2: The mean posttest level of satisfaction of communication board in ventilator patient in experimental group.

Section 3: The mean posttest level of satisfaction of communication in ventilator patient in control group.

Section 4: The mean posttest level of satisfaction of communication pattern in both experimental and control group.

\section{1 sample characteristics:-}

This section deals with the data pertaining to the sample characteristics of the subjects. It is presented and analyzed in terms of frequency and percentage distribution. Table 1 shows the distribution of sample characteristics with respect to subjects age, gender, education, occupation, duration of intubation, duration of weaning use of anxiolytics, diagnosis.

\section{Section 1: Frequency and percentage of socio-demographic variables of experimental and control group:-}

This section deals with the data pertaining to the base line information of ventilator patients. It is analyzed and presented in terms of frequency and percentage distribution. 


\section{Experimental group:-}

Table No.2 Frequency and percentage distribution of sample characteristics of experimental group.

$\mathrm{n}=10$

\begin{tabular}{|c|c|c|c|}
\hline \multirow{7}{*}{$\begin{array}{l}\text { Sl no. } \\
1 .\end{array}$} & Demographic variables & Frequency & Percentage $\%$ \\
\hline & Age in year & & \\
\hline & \multirow{2}{*}{ a) $21-30$} & 0 & $0 \%$ \\
\hline & & 1 & $10 \%$ \\
\hline & $\begin{array}{l}\text { b) } 31-40 \\
\text { c) } 41-50\end{array}$ & 6 & $60 \%$ \\
\hline & d) $51-60$ & 3 & $0 \%$ \\
\hline & e) $61-70$ & 0 & $0 \%$ \\
\hline \multirow[t]{3}{*}{2} & Gender & & \\
\hline & Male & 5 & $50 \%$ \\
\hline & Female & 5 & $50 \%$ \\
\hline \multirow[t]{5}{*}{3.} & Religion & & \\
\hline & a) $\quad$ Hindu & 7 & $70 \%$ \\
\hline & Muslim & 3 & $30 \%$ \\
\hline & Christian & 0 & $0 \%$ \\
\hline & d) Others & 0 & $0 \%$ \\
\hline \multirow[t]{7}{*}{4.} & Educational status & & \\
\hline & a) $\quad$ Illiterate & 2 & $20 \%$ \\
\hline & Primary & 1 & $10 \%$ \\
\hline & High school & 3 & $30 \%$ \\
\hline & Higher secondary school & 2 & $20 \%$ \\
\hline & Graduate & 2 & $20 \%$ \\
\hline & Doctorate & 0 & $0 \%$ \\
\hline \multirow[t]{3}{*}{5.} & Occupation & & \\
\hline & a) $\quad$ Employed & 8 & $80 \%$ \\
\hline & b) Unemployed & 2 & $20 \%$ \\
\hline \multirow[t]{3}{*}{6.} & Area of residence & & \\
\hline & a) $\quad$ Urban & 7 & $70 \%$ \\
\hline & b) $\quad$ Rural & 3 & $30 \%$ \\
\hline \multirow[t]{4}{*}{7.} & Duration of intubation & & \\
\hline & a) $\quad<2$ days & 7 & $70 \%$ \\
\hline & 2-5 days & 1 & $10 \%$ \\
\hline & $>6$ days & 2 & $20 \%$ \\
\hline \multirow[t]{4}{*}{8.} & Weaning duration & & \\
\hline & a) $\quad 2$ days & 7 & $70 \%$ \\
\hline & 3 days & 2 & $20 \%$ \\
\hline & 4 days & 1 & $10 \%$ \\
\hline \multirow[t]{3}{*}{9.} & Use of anxiolytics & & \\
\hline & a) $\quad$ Yes & $\begin{array}{l}5 \\
5\end{array}$ & $50 \%$ \\
\hline & b) $\quad$ No & 5 & $50 \%$ \\
\hline 10. & Diagnosis & & \\
\hline a) & Cardiovascular disease & 8 & $80 \%$ \\
\hline b) & Pulmonary disease & 2 & $20 \%$ \\
\hline c) & Renal disease & 0 & $0 \%$ \\
\hline d) & Gastro-intestinal & 0 & $0 \%$ \\
\hline e) & Neurological & 0 & $0 \%$ \\
\hline f) & Musculoskeletal & 0 & $0 \%$ \\
\hline g) & Surgical resection & 0 & $0 \%$ \\
\hline h) & Others & 0 & $0 \%$ \\
\hline
\end{tabular}


Control group:-

Table 3 : Frequency and percentage distribution of sample characteristics of control group $n=10$

\begin{tabular}{|c|c|c|c|}
\hline $\begin{array}{l}\text { Sl } \\
\text { no. }\end{array}$ & Demographic variables & Frequency & $\begin{array}{r}\text { Percentage } \\
\%\end{array}$ \\
\hline \multirow{6}{*}{1.} & \multicolumn{3}{|l|}{ Age in year } \\
\hline & a) $21-30$ & 1 & $10 \%$ \\
\hline & b) $31-40$ & 0 & $0 \%$ \\
\hline & c) $41-50$ & 2 & $20 \%$ \\
\hline & d) $51-60$ & 4 & $40 \%$ \\
\hline & e) $61-70$ & 3 & $30 \%$ \\
\hline \multirow[t]{3}{*}{2} & \multicolumn{3}{|l|}{ Gender } \\
\hline & c) $\quad$ Male & 8 & $80 \%$ \\
\hline & d) Female & 2 & $20 \%$ \\
\hline \multirow[t]{5}{*}{3.} & \multicolumn{3}{|l|}{ Religion } \\
\hline & e) Hindu & 9 & $90 \%$ \\
\hline & Muslim & 1 & $10 \%$ \\
\hline & Christian & 0 & $0 \%$ \\
\hline & Others & 0 & $0 \%$ \\
\hline \multirow[t]{7}{*}{4.} & \multicolumn{3}{|l|}{ Educational status } \\
\hline & g) $\quad$ Illiterate & 0 & $0 \%$ \\
\hline & Primary & 2 & $20 \%$ \\
\hline & High school & 3 & $30 \%$ \\
\hline & Higher secondary school & 4 & $40 \%$ \\
\hline & Graduate & 1 & $10 \%$ \\
\hline & 1) Doctorate & 0 & $0 \%$ \\
\hline \multirow[t]{3}{*}{5.} & \multicolumn{3}{|l|}{ Occupation } \\
\hline & c) $\quad$ Employed & 6 & $60 \%$ \\
\hline & d) Unemployed & 4 & $40 \%$ \\
\hline \multirow[t]{3}{*}{6.} & \multicolumn{3}{|l|}{ Area of residence } \\
\hline & c) Urban & 10 & $100 \%$ \\
\hline & d) $\quad$ Rural & 0 & $0 \%$ \\
\hline \multirow[t]{4}{*}{7.} & \multicolumn{3}{|l|}{ Duration of intubation } \\
\hline & d) $\quad<2$ days & 4 & $40 \%$ \\
\hline & $2-5$ days & 4 & $40 \%$ \\
\hline & f) $>6$ days & 2 & $20 \%$ \\
\hline \multirow[t]{4}{*}{8.} & \multicolumn{3}{|l|}{ Weaning duration } \\
\hline & d) $\quad 2$ days & 2 & $20 \%$ \\
\hline & 3 days & 3 & $30 \%$ \\
\hline & f) 4 days & 5 & $50 \%$ \\
\hline \multirow[t]{2}{*}{9.} & \multicolumn{3}{|l|}{ Use of anxiolytics } \\
\hline & $\begin{array}{ll}\text { c) } & \text { Yes } \\
\text { d) } & \text { No }\end{array}$ & $\begin{array}{l}0 \\
10\end{array}$ & $\begin{array}{l}0 \% \\
100 \%\end{array}$ \\
\hline 10. & Diagnosis & & \\
\hline & i) Cardiovascular disease & 3 & $30 \%$ \\
\hline & Pulmonary disease & 1 & $10 \%$ \\
\hline & Renal disease & 1 & $10 \%$ \\
\hline & Gastro-intestinal & 4 & $40 \%$ \\
\hline & Neurological & 1 & $10 \%$ \\
\hline & Musculoskeletal & 0 & $0 \%$ \\
\hline & Surgical resection & 0 & $0 \%$ \\
\hline & Others & 0 & $0 \%$ \\
\hline
\end{tabular}




\section{Experimental group}

Data presented in Table No.1 reveals that $6(60 \%)$ ventilator patients were between age group of 41-50 years \& $1(10 \%)$ in $31-40$ age group.

Regarding the gender of mechanical ventilated patients males were $5(50 \%)$ and females were $5(50 \%)$ both are same.

Regarding religion majority are Hindus were 7(70\%), Muslims were 3(30\%) and Christians were $0(0 \%)$, others also 0

Regarding educational status majority of patients are studied in high school were 3(30\%), primary were $1(10 \%)$, higher secondary were $2(20 \%)$, graduate were $2(20 \%)$,

doctorate were $0(0 \%)$, and illiterate were $2(20 \%)$

Regarding occupation the employees are 8(80\%) and unemployed are 2(20\%).

Regarding Area of residence the patients who are living in urban area were 7(70\%) and in rural area were 3(30\%)

Regarding duration of intubation less than 2 days were 7(70\%), between 2-5 days were $1(10 \%)$ and > 6days were $2(20 \%)$.

Regarding weaning duration in 2days were 7(70\%), in 3 days 2(20\%) and in 4 days

$1(10 \%)$

Regarding use of anxiolytics for the ventilated patients are 5(50\%) and no use were

$5(50 \%)$

Regarding the diagnosis majority of patients having cardiovascular disease were $8(80 \%)$ and the pulmonary disease were $2(20 \%)$ and others were $0(0 \%)$

It was found that majority of ventilated patients are 6(60\%) in age group 41-50 years. both the male and female having same 5(50\%). Majority are Hindus were 7(70\%). In educational status most of the patients are studied in high school were 3(30\%). Most of the patients are living in urban area were 7(70\%). majority of patients are employed were $8(80 \%)$. most of patients intubated in the duration of less than 2 days were $7(70 \%)$. $7(70 \%)$ having the weaning duration of 2 days. majority of ventilator patients used anxiolytics were $5(50 \%)$. most of the patients having cardiovascular disease were $8(80 \%)$.

\section{Control group:-}

Data presented in Table No.2 reveals that $4(40 \%)$ ventilator patients were between age group of 51-60 years \& $3(30 \%)$ in $61-70$ age group.

Regarding the gender of mechanical ventilated patients males were $8(80 \%)$ and females were $2(20 \%)$

Regarding religion majority are Hindus were $9(90 \%)$, Muslims were $1(10 \%)$ and Christians were $0(0 \%)$, others also 0

Regarding educational status majority of patients are studied in high secondary school were 4(40\%), high school were $3(30 \%)$, primary were $2(20 \%)$, graduate were $1(10 \%)$,

doctorate were $0(0 \%)$, and illiterate were $0(0 \%)$

Regarding occupation the employees are 6(60\%) and unemployed are 4(40\%). Regarding Area of residence the patients who are living in urban area were $10(100 \%)$

and in rural area were $0(0 \%)$

Regarding duration of intubation less than 2 days were 4(40\%), between 2-5 days were 4(40\%) and > 6days were $2(20 \%)$.

Regarding weaning duration in 2days were 2(20\%), in 3 days 3(30\%) and in 4 days

$5(50 \%)$

Regarding use of anxiolytics for the ventilated patients are $0(0 \%)$ and the patients not used the anxiolytics were $10(100 \%)$

Regarding the diagnosis majority of patients having gastro intestinal disease were $4(40 \%)$ and the cardiovascular disease were $3(30 \%)$,pulmonary disease were $1(10 \%)$, renal disease were $1(10 \%)$ and neurological disease were $1(10 \%)$ and others were 0

It was found that majority of ventilated patients are 4(40\%)in age group 51-60 years. the male having $8(80 \%)$ and female 2(20\%). Majority are Hindus were 9(90\%). In educational status most of the patients are studied in high secondary school were $4(40 \%)$. Most of the patients are living in urban area were 10(100\%). majority of patients are employed were $6(60 \%)$. most of patients intubated in the duration of less than 2 days were 4(40\%). 5(50\%) having the weaning duration of 4days. majority of ventilator patients are not used anxiolytics were $10(100 \%)$. most of the patients having cardiovascular disease were 4 (40\%). 


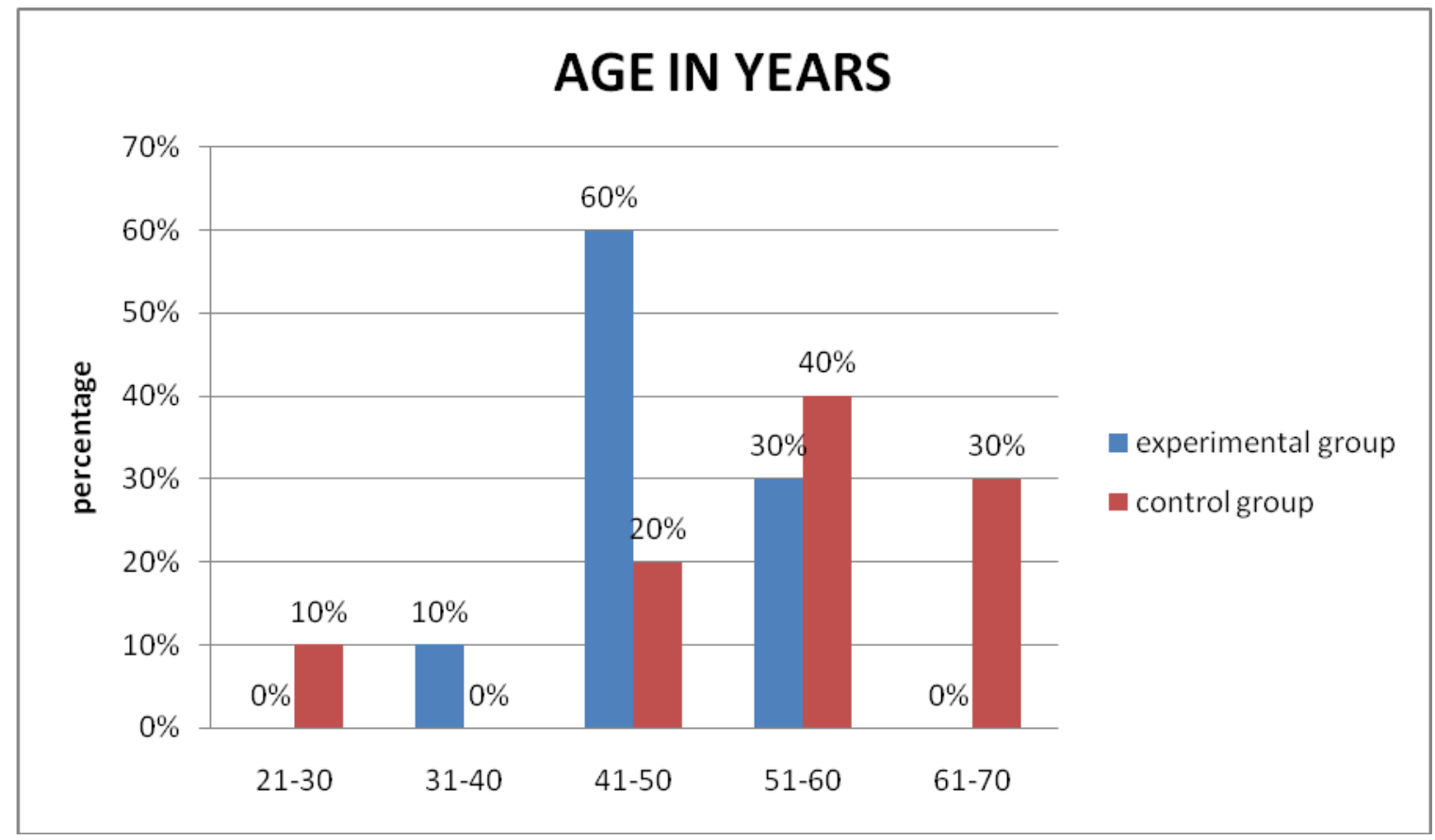

Figure 1: Diagram showing distribution of age in years in both experimental and control group

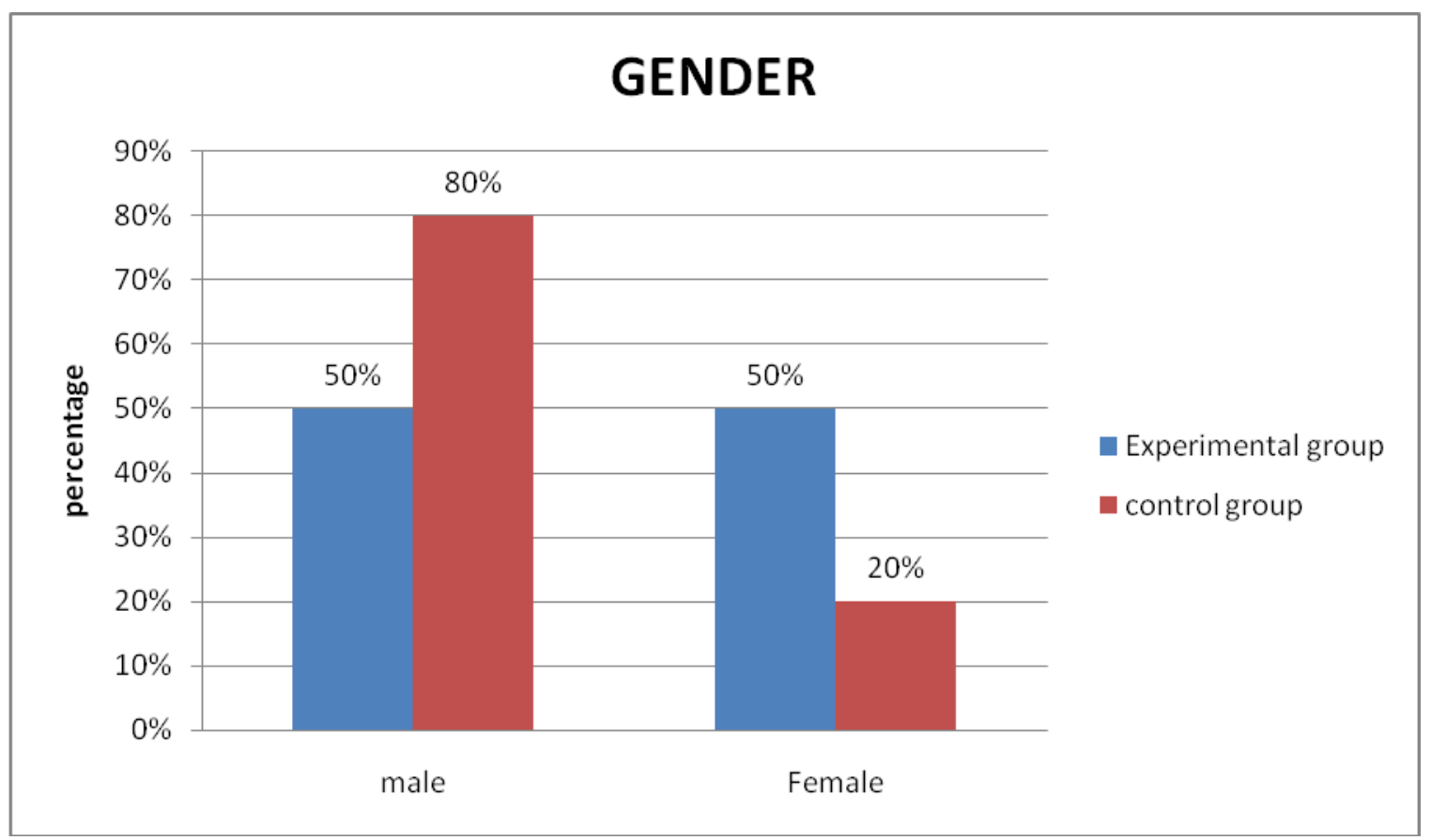

Figure 2: Diagram showing distribution of gender in both experimental and control group 


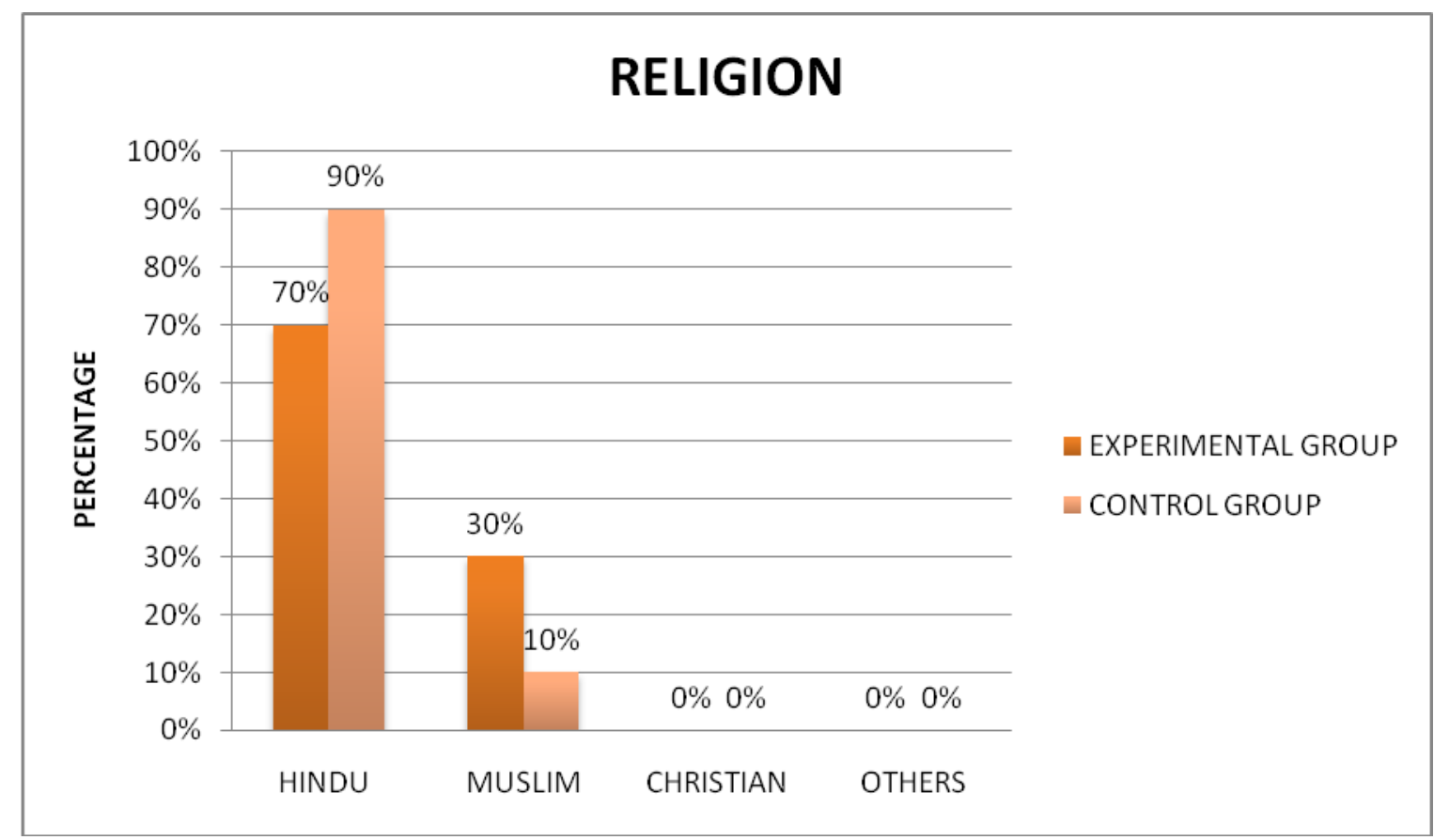

Figure 3: Diagram showing distribution of religion in both experimental and control group

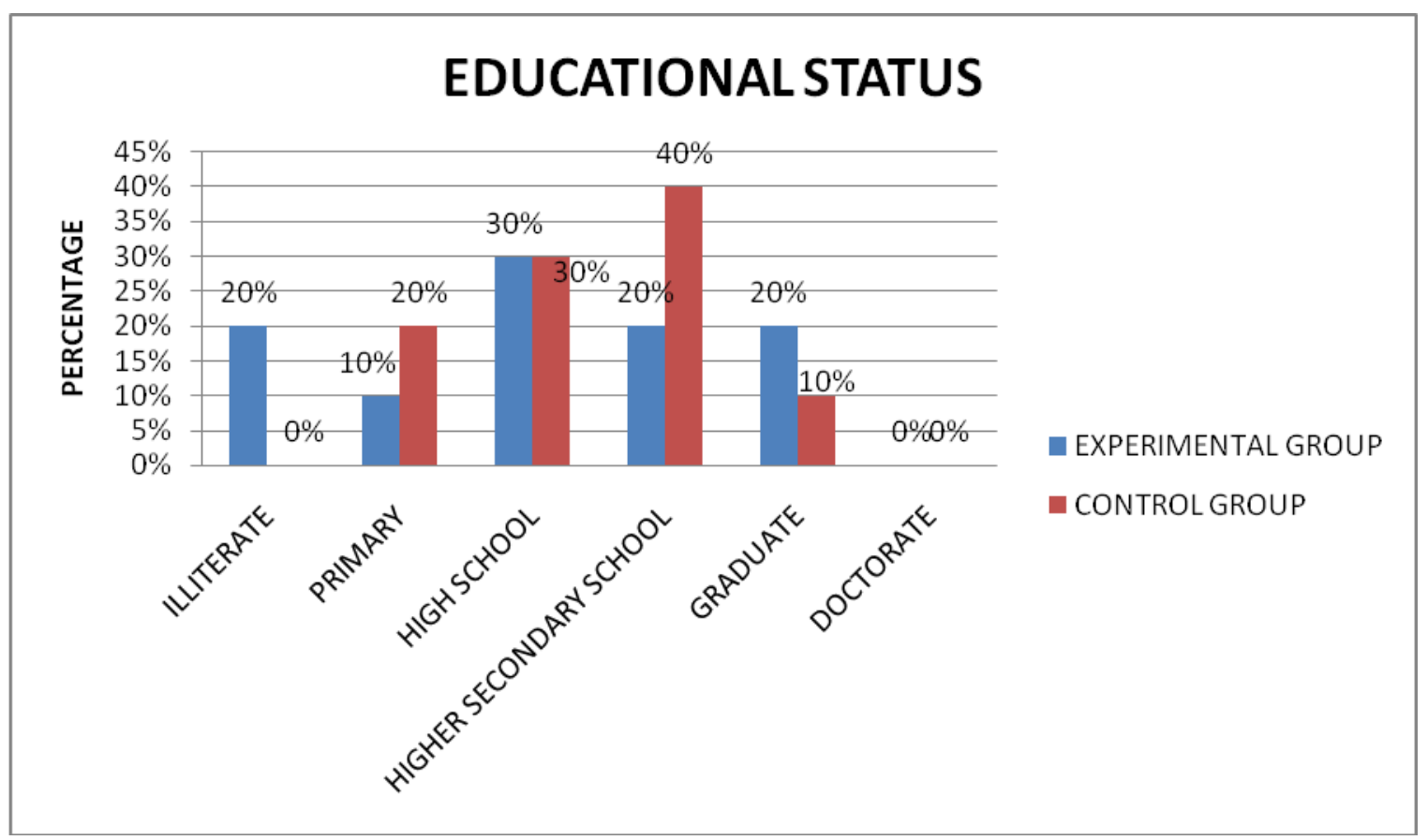

Figure 4: Diagram showing distribution of educational status in both experimental and control group 


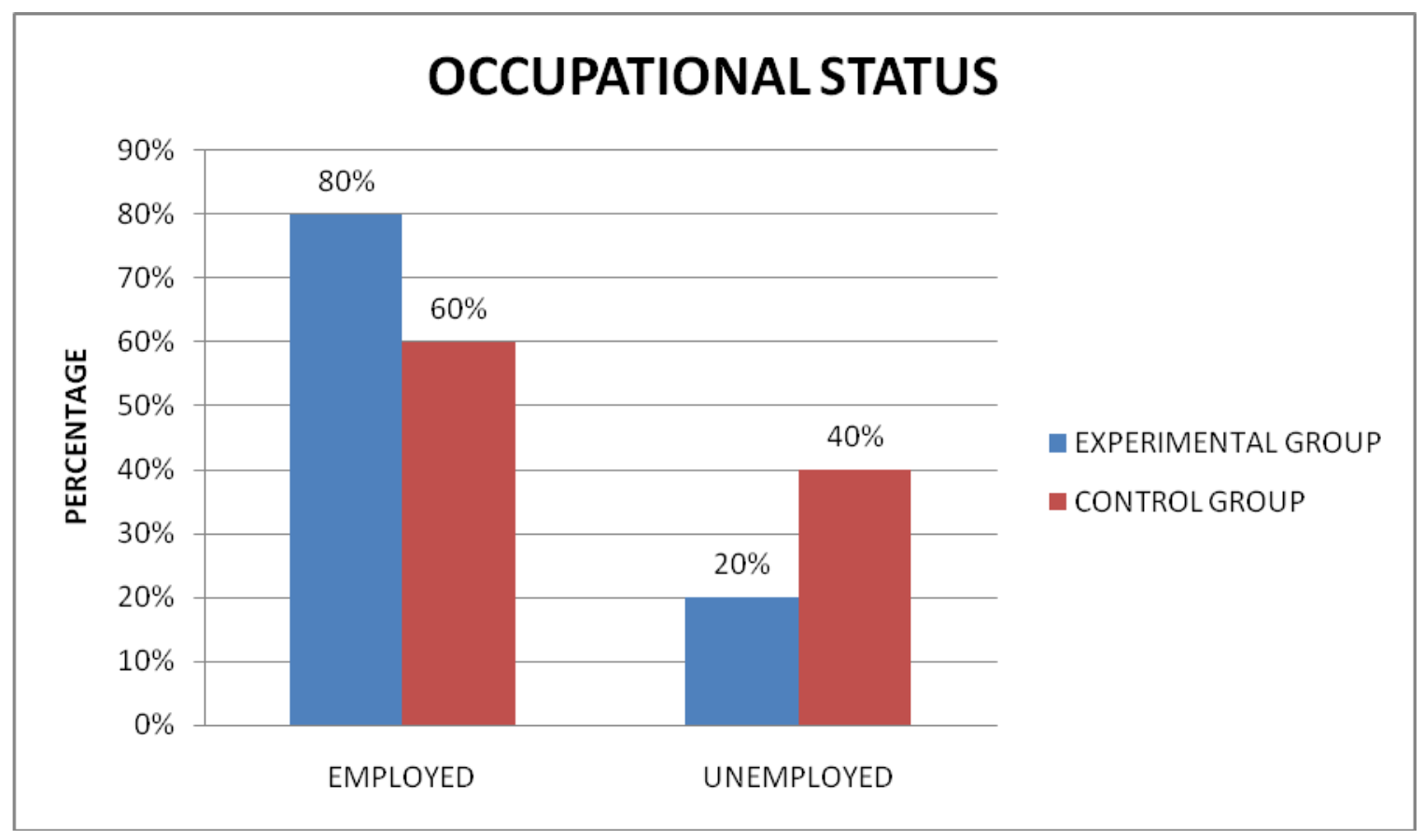

Figure 5: Diagram showing distribution of occupational status in both experimental and control group

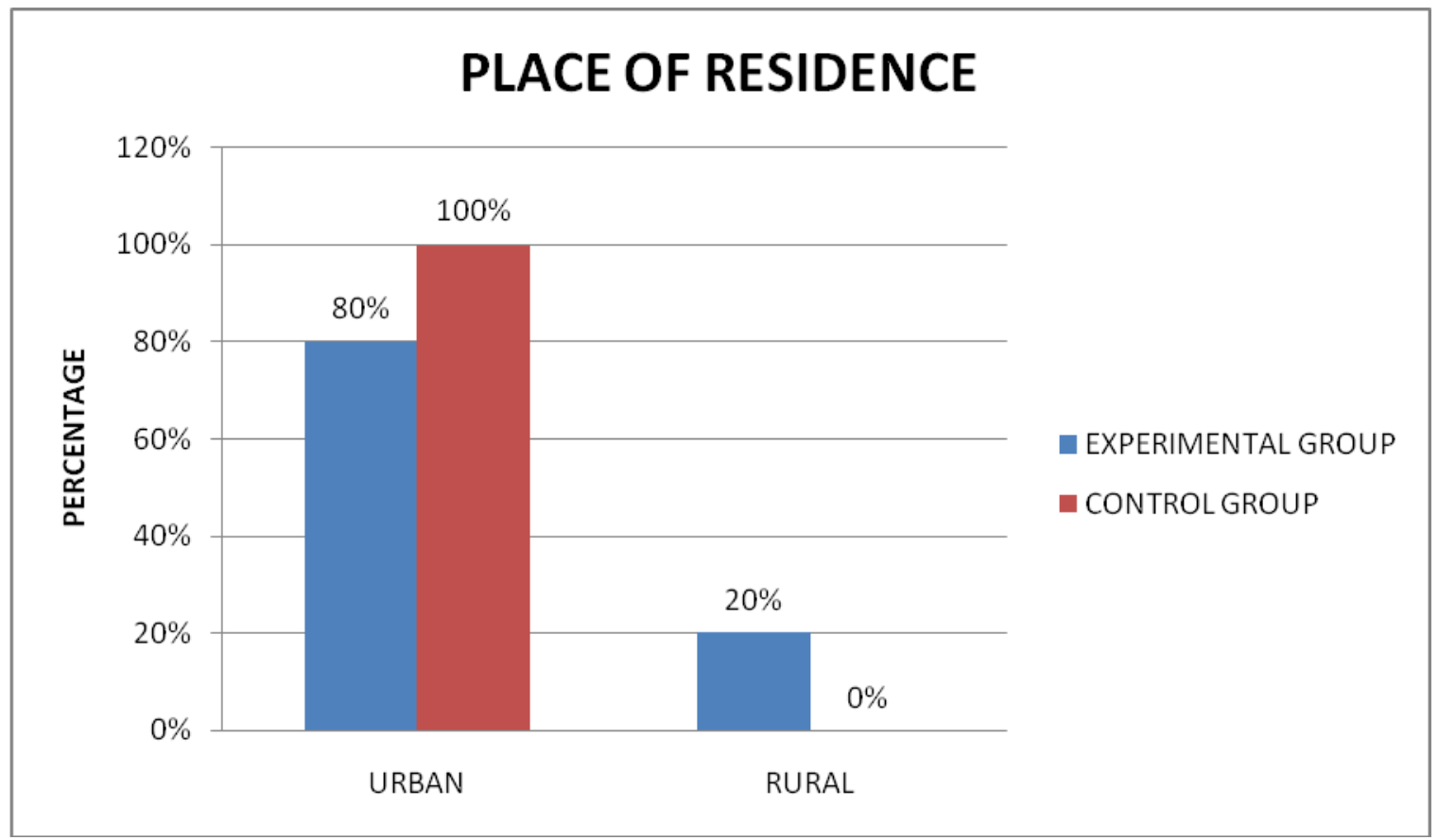

Figure 6: Diagram showing distribution of place of residence in both experimental and control group 


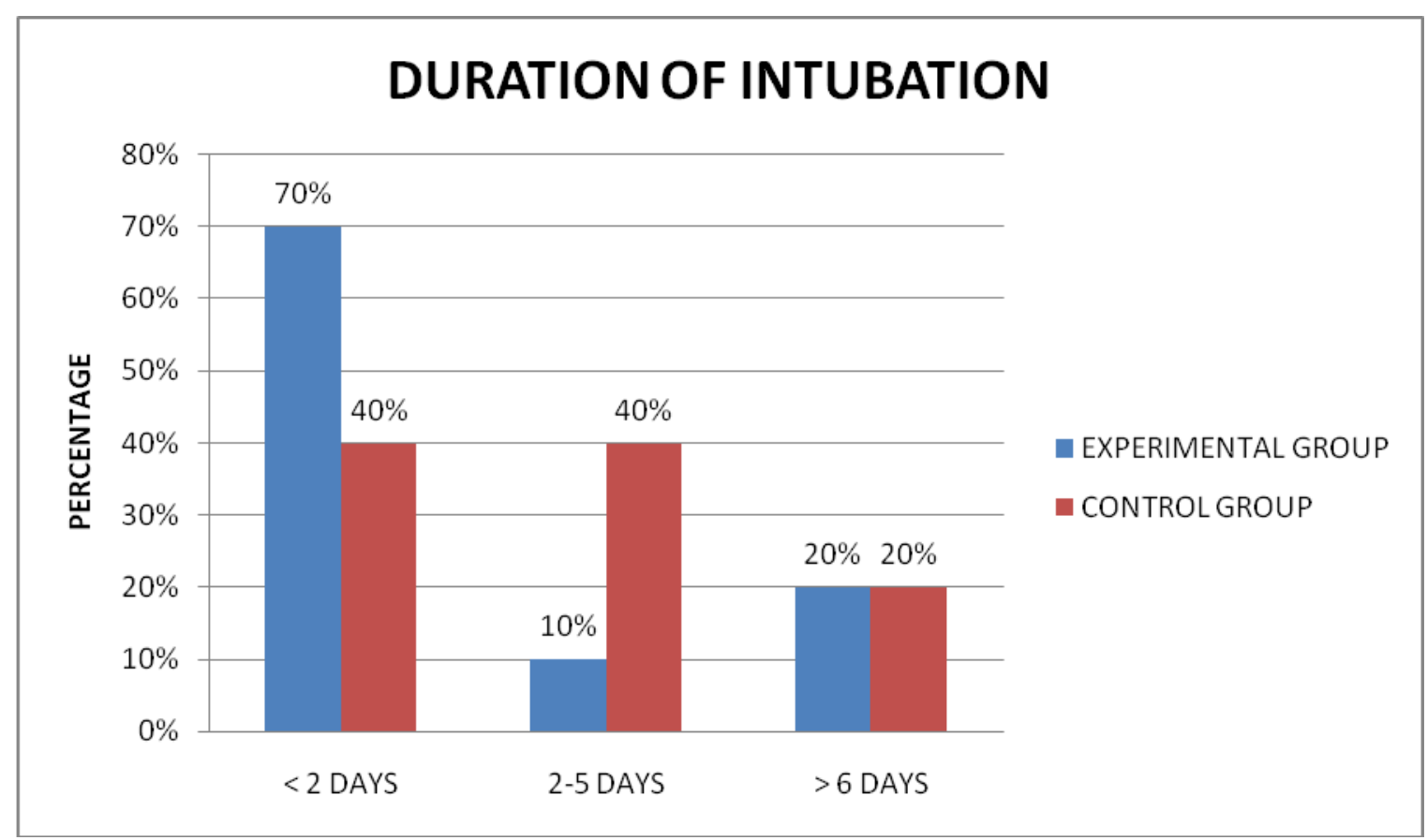

Figure 7: Diagram showing distribution of duration of intubation in both experimental and control group

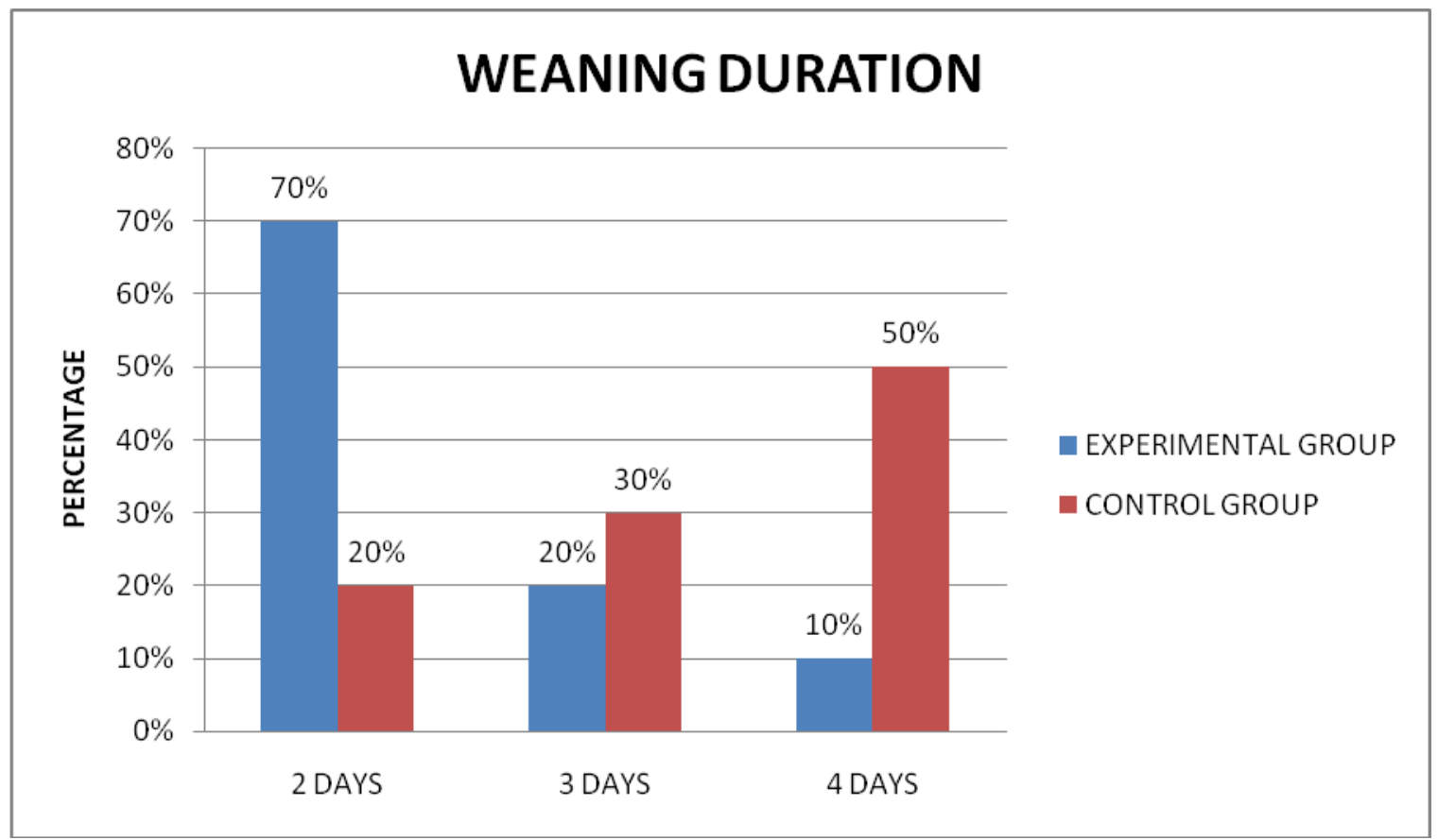

Figure 8: Diagram showing distribution of weaning duration in both experimental and control group 


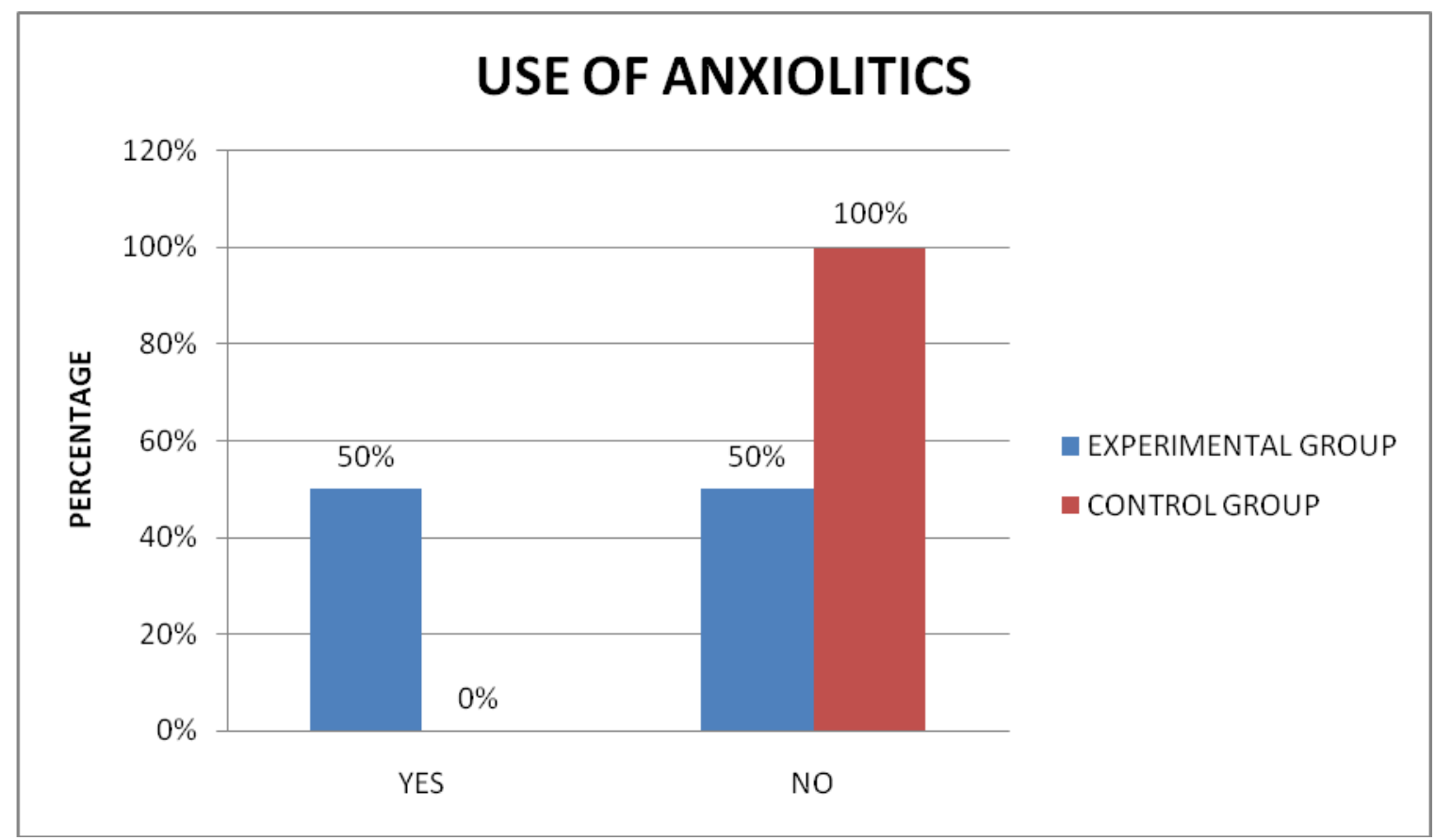

Figure 9: Diagram showing distribution of use of anxiolytics in both experimental and control group

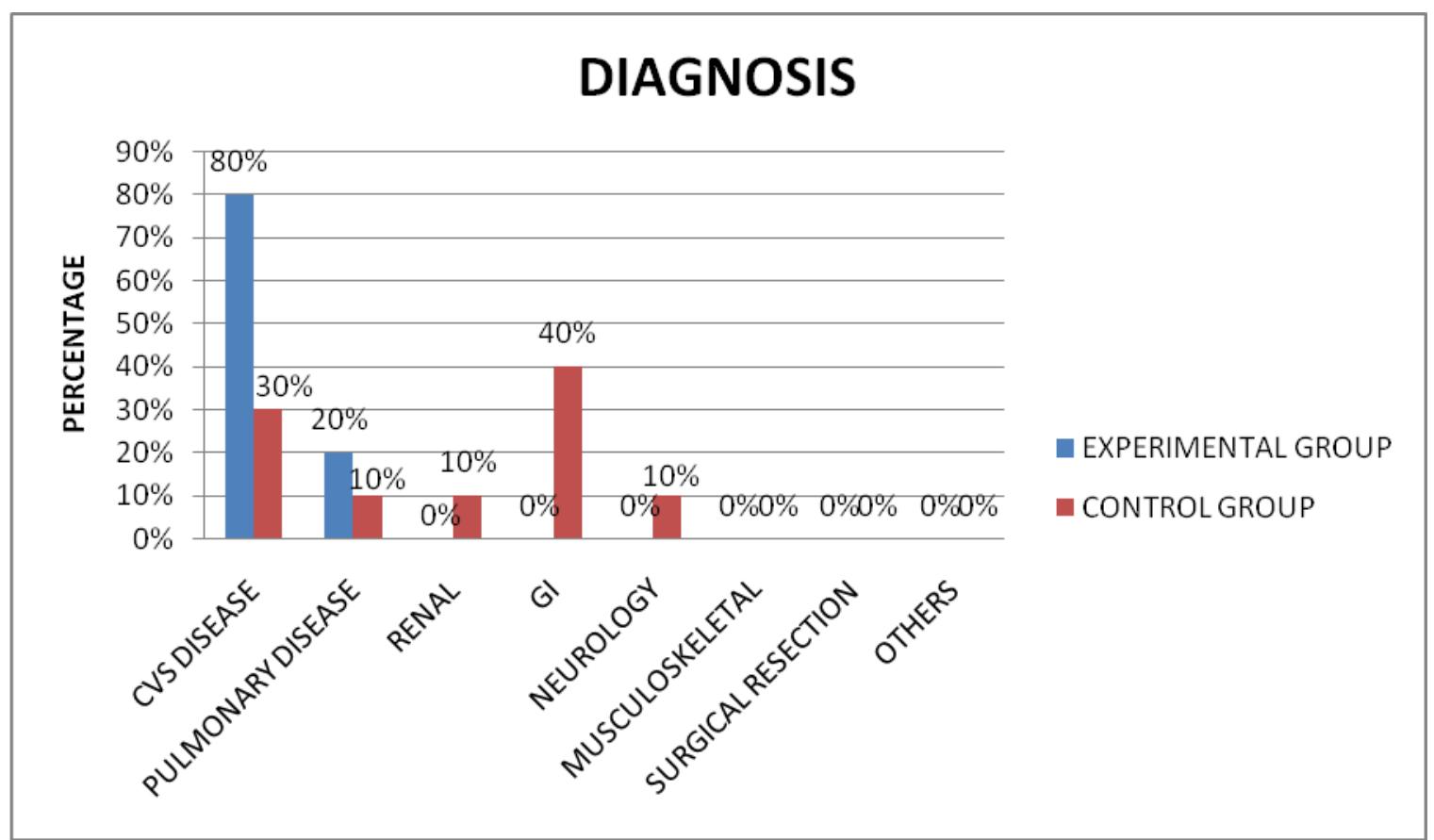

Figure 10: Diagram showing distribution of diagnosis in both experimental and control group 
Section 2: The mean posttest level of satisfaction of communication board in ventilator patient in experimental group

Experimental group:-

Table no 4 showing the mean posttest level of satisfaction of communication board in ventilator patient in experimental group.

$\mathrm{n}=10$

\begin{tabular}{|c|c|c|c|c|c|c|}
\hline Score & $\begin{array}{l}\text { Level of } \\
\text { satisfaction }\end{array}$ & Frequency & Percentage & $\begin{array}{l}\text { Mean } \\
\text { score }\end{array}$ & Mean\% & S.D \\
\hline 17- 34 & Not satisfied & $\mathbf{0}$ & $\mathbf{0}$ & \multirow{3}{*}{46.4} & \multirow{3}{*}{68.23} & \multirow{3}{*}{3.33} \\
\hline $35-51$ & $\begin{array}{l}\text { To } \\
\text { extent }\end{array}$ & 10 & 100 & & & \\
\hline $52-68$ & Satisfied & $\mathbf{0}$ & $\mathbf{0}$ & & & \\
\hline
\end{tabular}

In the above table shows the mean posttest value of level of satisfaction of communication board in ventilator patient in experimental group in which percentage of satisfaction of communication pattern using the communication board in ventilator patients is $100 \%$ and mean is 46.4 and percentage of mean is $68.23 \%$. The standard deviation is 3.33 .

Section 3: The level of satisfaction of communication in ventilator patient in control group

Control group

Table no 5 shows the level of satisfaction of communication in ventilator patient in control group.

$\mathrm{n}=10$

\begin{tabular}{|c|c|c|c|c|c|c|}
\hline Score & $\begin{array}{l}\text { Level of } \\
\text { satisfaction }\end{array}$ & Frequency & Percentage & $\begin{array}{l}\text { Mean } \\
\text { score }\end{array}$ & Mean\% & S.D \\
\hline $17-34$ & Not satisfied & 5 & $50 \%$ & \multirow{3}{*}{32.9} & \multirow[b]{3}{*}{48.38} & \multirow{3}{*}{5.088} \\
\hline $35-51$ & $\begin{array}{ll}\text { To } & \text { some } \\
\text { extend } & \\
\end{array}$ & 5 & $50 \%$ & & & \\
\hline $52-68$ & Satisfied & $\mathbf{0}$ & $\mathbf{0}$ & & & \\
\hline
\end{tabular}

In the above table shows the mean posttest value of level of satisfaction of communication without using communication board in ventilator patient in control group, in which percentage of level of satisfaction of communication pattern using the communication board in ventilator patients is $50 \%$ and not satisfied is $50 \%$. The mean is 32.9 and percentage of mean is $48.38 \%$. The standard deviation is 5.088 .

Section 4: The comparison of posttest level of satisfaction of communication pattern in both experimental and control group.

Table no. 6 showing the mean posttest level of satisfaction of communication pattern in both experimental and control group.

$\mathrm{n} 1=10, \mathrm{n} 2=10$

\begin{tabular}{|c|c|c|c|l|l|}
\hline Groups & Mean & Mean\% & Mean deviation & ' $\mathrm{t}$ ' value & Remark \\
\hline Experimental group & 46.4 & 68.23 & 13.5 & $7.00^{*}$ & Significant \\
\hline Control group & 32.9 & 48.38 & & & \\
\hline
\end{tabular}

$\mathrm{t}(18)=2.18 \leq 0.05$ level, $*$ Significant 


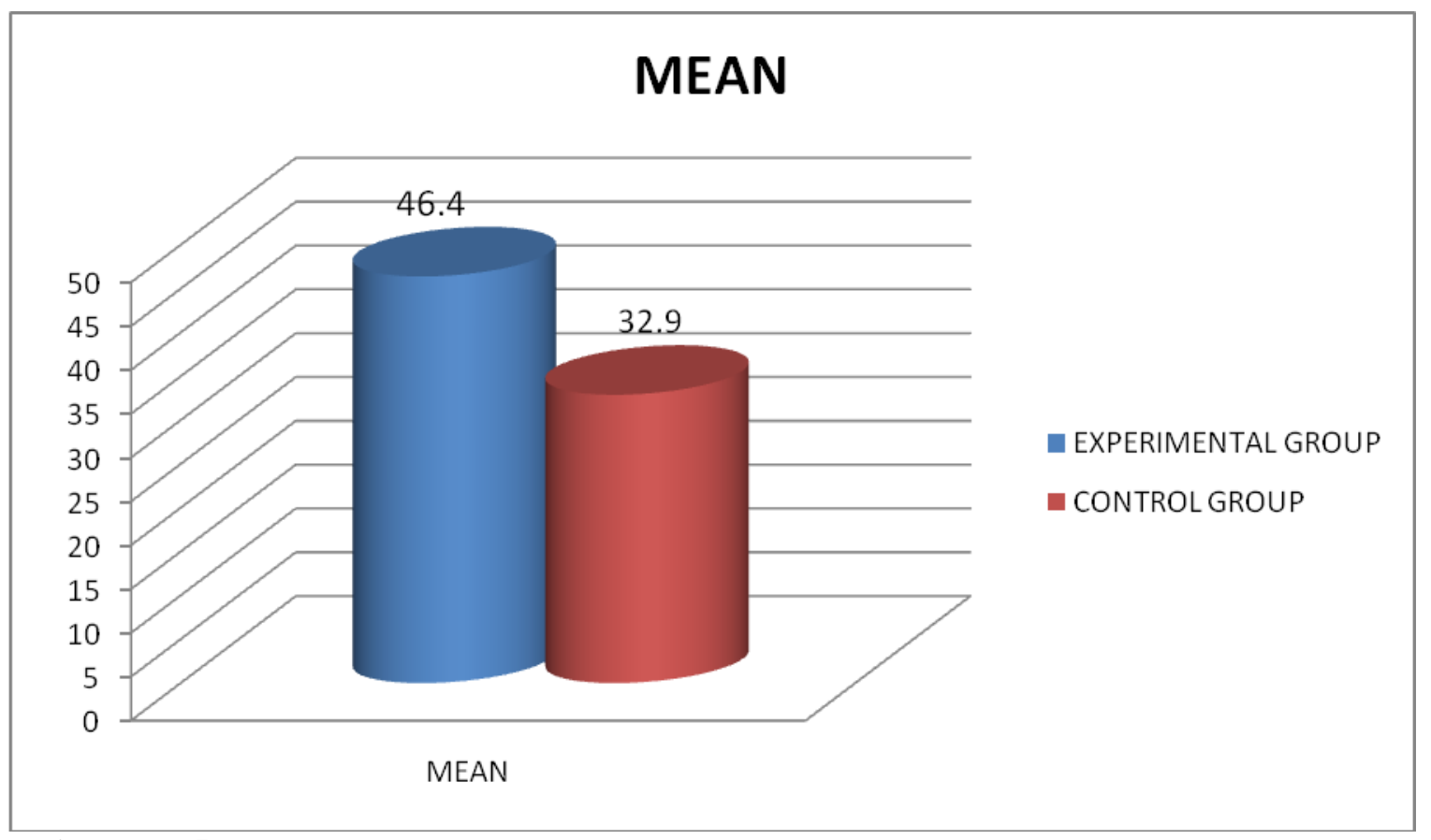

Figure no. 5 -showing the mean posttest level of satisfaction of communication pattern in both experimental and control group.

In the above table it is shown the mean posttest of experimental and control group, where the mean deviation is 13.5 and the ' $t$ ' value is $7.00^{*}$. This represent that ${ }^{\prime} t(18)=2.18 \leq 0.05$ level and the significant level of communication board is highly effective in mechanical ventilator patient.

\section{Summary:-}

This chapter deals with the sample characteristics, frequency and percentageof socio demographic variables of control and experimental group.

Discussion, summary, conclusions, recommendation, implications \& limitations:-

This chapter deals with discussion, summary, conclusion, recommendations, implications with clinical practice and limitation.

Statement of the problem:-

"A study to assess the effectiveness of communication board on the level of satisfaction of communication pattern among patients on mechanical ventilator in Bombay hospital, Indore."

\section{Objectives:-}

The objectives of the study are as follows:

- Assessed the post-test level of communication pattern among the patient on ventilator in both experimental and control group

- Compared the post-test level of satisfaction of communication board among patient on mechanical ventilator between experimental and control group

Hypothesis:-

There is significant difference in mean posttest level of satisfaction in communication pattern among the patients on mechanical ventilator between experimental and control group. 


\section{Discussion:-}

- This chapter, major findings of this study are discussed in the line with objectives, hypothesis, and review of literature is related to similar study.

- Score of satisfaction level of communication among mechanical ventilator patient.

- The finding demonstrated good satisfaction level in communication pattern among mechanical ventilator patient.

- On the basis of findings the hypothesis is accepted.

- Mean posttest level of satisfaction of communication pattern among ventilator patient.

\section{Conclusion:-}

After the detailed analysis, this study leads to the following conclusion:-

That the level of satisfaction of communication pattern in mechanical ventilator patients using communication board is highly significant than those who had underwent study without communication board.

There was a highly significant level of satisfaction of communication pattern in experimental group than control group , the unpaired [t] test computed between mean posttest of experimental and control group score (7.00*) which indicated a highly significant in level of satisfaction of communication board in mechanical ventilator patients

Thus it is concluded that the communication board is effective in mechanical ventilator patients, who are unable to speak .hence on the basis of above cited findings, it could be concluded undoubtedly that the written material prepared by the investigator in the form of communication board helped the patient to exchange the ideas, information and facts to the health care provider regarding the basic requirements, needs and communication pattern in mechanical ventilator patients.

\section{Implications:}

The findings of the study have implications for nursing practice, nursing education, nursing administration and nursing research.

- Nursing practice:

Continuous in-service education is an important tool for health care agency. The findings of the study indicated that there is a need for the continuous in-service education regarding communication board to improve the level of satisfaction of communication in mechanically ventilated patient and to find out the problems of patient and to improve the quality care.

- Nursing education:

o Awareness can be given to the nursing staff and family members so as to improve the communication pattern with mechanically ventilated patient.

o It can be used as an informational aid to student nurse to acquire the knowledge and skills in enabling effective communication with mechanically ventilated patient.

o The nursing curriculum has to focus on enabling the nursing students to develop communication skills using communication board in mechanically ventilated patient.

o Nursing personnel working in various health care setting should be given in-service education to update knowledge and planning appropriate interventions to improve communication pattern in mechanical ventilated patient.

- Nursing administration:

The present study is proposed to help the hospital administrator to strategically plan and meet the health needs of mechanically ventilated patient who are unable to communicate their problems and basic needs effectively with the use of communication board.

- Nursing research

There is a need for extended and intensive nursing research in the areas of Intensive Care Unit. Especially in India only few studies were reported regarding effectiveness of communication board in level of satisfaction of communication in mechanically ventilator patient. It is important to know the level of satisfaction of communication pattern in mechanically ventilated patient. 


\section{Limitations:-}

A few limitations of the study are listed below:

1. The finding of the study cannot be generalized because of the small sample 20

2. Limited time was available for data collection.

3. The finding of the study cannot be generalized because of the small sample 20

4. Limited time was available for data collection.

5. Structured knowledge questionnaire was used for data collection which restricted the amount of information that could be obtained from the mechanically ventilator patient.

\section{Recommendations:-}

On the basis of findings of the study, it is recommended that:

- A similar study can be repeated by taking a large sample to generalize the findings.

- A comparative study may be conducted to find out the effectiveness of communication board on level of satisfaction in mechanically ventilator patient regarding the same topic.

- A study can be conducted to identify level of satisfaction of communication board in mechanically ventilator patient.

In order to examine the effectiveness of communication board on level of satisfaction of communication pattern among patients on mechanical ventilator was formulated that the mean posttest in experimental group is significantly higher than mean posttest in control group. The study assumed that communication board is effective in mechanically ventilator patient.

The present study is based on the concept of communication board to the conscious patients on mechanical ventilator.

The investigator adopted the Widenbach's helping art of clinical art theory (1964), which describes the desired situation and way to attain. It directs action towards the explicit goals.

This study made use of a qualitative study with experimental and control group posttest research design. The mechanically ventilator patient in Bombay hospital, Indore. Non-probability sampling technique was utilized to select 10 patients in mechanical ventilator in experimental and control group in ICU based on certain determined criteria.

The investigator prepared a structured knowledge questionnaire consisting of 17 questions to assess the level of satisfaction of communication board on mechanically ventilated patients in ICU in experimental group with communication board and control group without communication board.

The actual study was conducted on 20 patients on mechanically ventilator in Bombay Hospital, Indore.

Following the posttest planned teaching on communication board on mechanical ventilator patient. The data obtained were analyzed in terms of objectives and hypotheses using descriptive and inferential statistics.

Findings of the study proved that the communication board on level of satisfaction on mechanical ventilator patient. The mean posttest score in experimental group was 46.4 and the mean posttest score of control group was 32.9. The posttest score proved that the communication board on level of satisfaction on mechanical ventilator to improve the communication pattern in experimental group than control group without communication board. The effectiveness of communication pattern in mechanical ventilator patient was tested in terms of level of satisfaction in communication and finding showed that it was significant at $7.00 *$ Level. Where* represents" value $\mathrm{t}(18)=2.18 \leq 0.05$ level.

On the whole, carrying out the study was really an exciting experience to the investigator. It also helped a great deal to explore and improve the level of satisfaction in communication pattern of mechanically ventilated patient and the researcher.

\section{Summary:-}

Summary includes objectives, hypotheses, assumptions, tool used for the study and findings of the study. 


\section{Bibliography:-}

\section{Books:-}

1. Cone NI, Walsh TS. Prolonged mechanical ventilation in critically ill patient: epidemiology, outcome \& modeling the potential cost consequenses of establishing a regional weaning unit: Journal of critical care, 2011, March $27 ; 15(2): 102$.

2. Rath M kleinpell, Patak E, Wilson stronks A, Costello J, Pearson C, Hennemen EA, Happ M.B. communication in ICU, Advance for nurses , 2008 December 10;6 : 18- 20.

3. GawlinskiA, Patak E, Fung NI, Berg J, Communication board in critical care: ptviews , Applied Nursing Research 2006, 19(4) 182-190.

4. Susan sereika, Katheryn Garret, Mary Beth Happ\& Judith Talk. The study of patient nurse effectiveness with assisted communication strategies : Contemporary clinical trials. 2008 September; 29(5); 801-808.

5. BKMAHAJAN (2010), " methods in bio statistics MAHAJAN (2010), " methods in bio statistics for medical students and research worker ", Jaypee publications, $7^{\text {th }}$ edition. $175-180$

6. BT BASAVANTHAPPA (2008), nursing research, published by Lippincott William Wilkins, 5th edition. 220, 742

7. BT BASAVANTHAPPA (2007), "nursing theories" published by jaypee, $1^{\text {st }}$ edition.169- 171

8. CR KOTHARI (2005), "research methodology', newdelhi international publisher.120-123

9. DENISE F POLIT (1999), "nursing research principles and methods" L ippincott publisher 6 ${ }^{\text {th }}$ edition.225-227

10. POLIT HUNGLER (1995), "nursing research principles and methods ,J.B. publication, $5^{\text {th }}$ edition. 150-155,199.

11. SUZANNE C. SNELTZER,et al(2011), medical surgical nursing, south Asian: Wolter Kluwer.1203

12. LIPPINCOTT (2006), Manual of nursing practice, Indian: Jaypee publication.167-168

13. LEWIS: et al(2011),medical surgical nursing,south Asian : Elsevier.

14. JOYCE.M.BLACK. et al (2005), medical surgical nursing, south east asia: Elsevier. 1104-1108

15. IGNATAVICIUS, et al(2013),medical surgical nursing,USA ; Elsevier. 1212-1216

16. BRUNNER and SIDDARTH'S (2004), medical surgical nursing, 10thedition,Lippincott William Wilkins,Philadelphia, 1608-1611

17. LINDA D, UNDIN et al (1992), Essential of critical care nursing. C.V. Mosby Publication,St. Louis. 1921-1929

18. LUCKMAN (1997).Saunder's Manual of nursing care .W.B. Saunders company,Philadelphia.1708-1711

19. TREECE, E.W. and TREECE, J.W.(1994). Elements of the research in nursing, 5thedition,Mosby, Philadelphia.321-32

20. UDWADIA, Farok L, Erach(1997): Principles of critical care. $3^{\text {rd }}$ edition. Oxford University Press, Delhi.534540

21. THARINO, PAUL, L.(1998).The ICU Book. $2^{\text {nd }}$ edition. Williams and Williams, Baltimore.432-430

22. BLACK, J.M. (1980). Medical surgical nursing, $5^{\text {th }}$ edition, W.B. Saunders Company, Singapore.121-129

23. LUCKMEN and SORENSEN (1987). Medical surgical nursing. $3^{\text {rd }}$ edition, W. B. Saunders Company, Philadelphia.325-329

24. LEWIS.H.D.(2004). Medical surgical nursing. $6^{\text {th }}$ edition. Missouri.Mosby $1231-1241$.

\section{Journals:-}

1. Patak .L .GawlinskiA,Berg, (2004) Patients reports of Health care practitioner interventions related to communication during mechanical ventilator ,Heart and Lung. The journal of acute and critical care, 308-320.

2. Patak .L .Wilson ,Happ M.B. (2009) . improving patient provider communication : The journal of nursing administration ,372-390.

3. Wilson-Stronks A, Costello.J, Kleinpell R M, Person C, Henneman E A, Happ.M.B, Improving patient-provider communication, Journal of Nursing Administration. 2009, September:39(9):372-376

4. Henneman.,Molayeme\& Cooper (2001) \& (2002) for mechanically sventilated patients. 512-524.

5. Patak .L .Gawlinski, Berg J.(2006), Communication board in critical care ; Applied nursing research , $182-190$. ss

6. Carroll, S M (2004) Non vocal ventilated patient perform of being Understood, western journal of nursing research $26(1), 85-103$.

7. Neetham D. M, Bronskill. SE, Calinawan J. R, Projected incidence of mechanical ventilation in Ontarioto to 2026 Preparing for the aging baby boomers: Journal of critical care medicine, 2005,March:33(3): 574-579

8. Hweidi M. Jordanian patient's perception of stressors in critical care units. International Journal for nursing students, 2007 February:44(2): 227-235

9. Jill V Radtke, Brooke M Baumann, Kathrynl. Garette, Mary Beth Happ, Journals of palliative medicine 2011 June:14(6) 791-795 